\title{
OPTIGAL TECHNOLOGIES IN FUTURE CNES MISSIONS
}

\section{EARTH OBSERVATION, SGIENGE, TELEGOM}

Bruno CUGNY Deputy Head of Instrumental Systems Department

International Conference on Space Optics - 9-12 October 2018, Chania, Greece (ICSO 2018)

... ceses. 


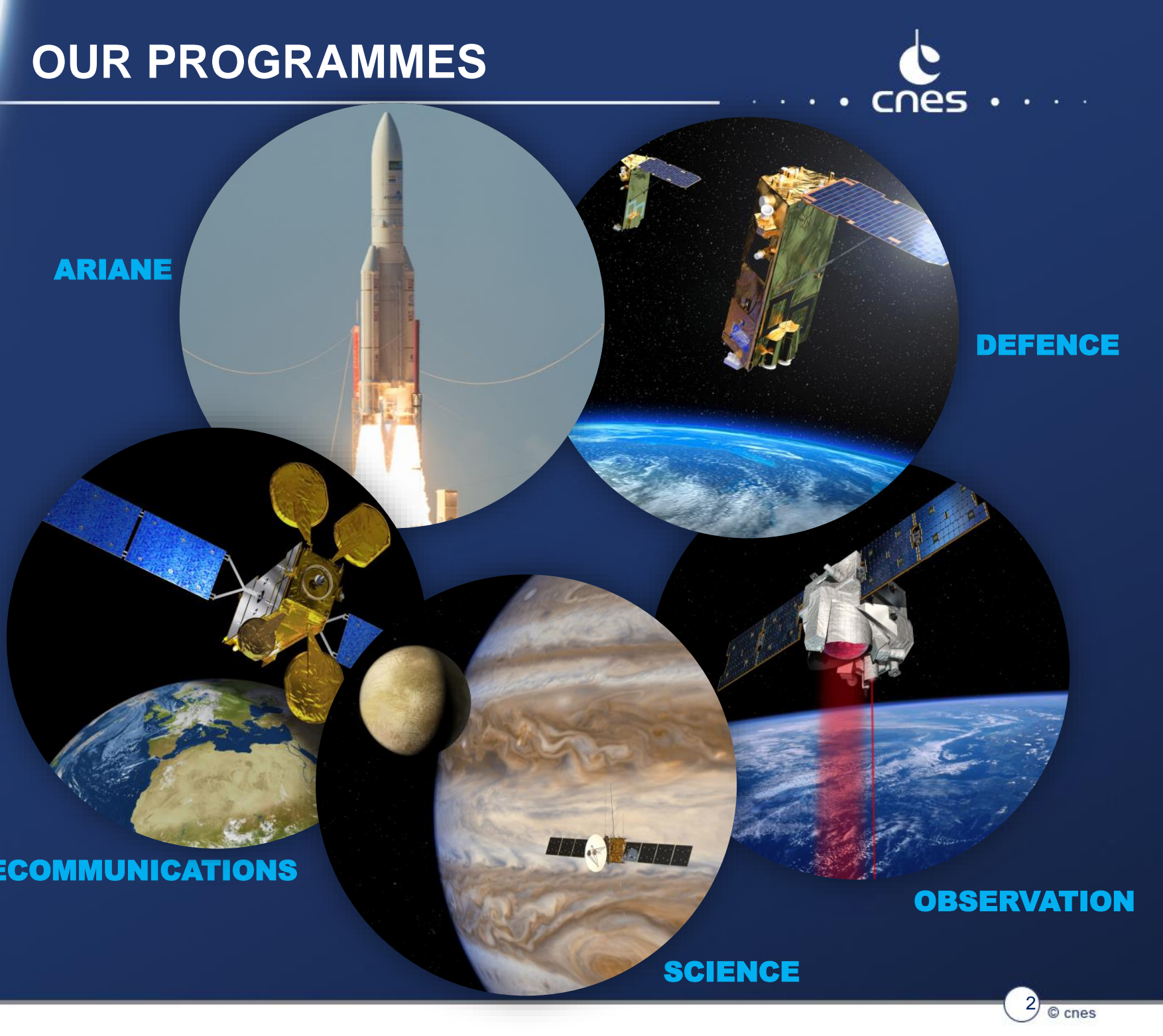




\section{CNES}

\section{Supervisory} ministries

\section{and its Partners}

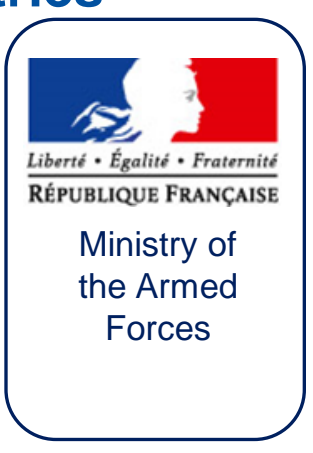

* Ministries:

$>$ for Ecological and Inclusive Transition

$>$ for Europe and Foreign Affairs

$>$ for Social Welfare and Health

$>$ for the Interior...

* General Commissariat for Investment

* National research organisations

* Growing number of International partners (NASA, JAXA, ROSCOSMOS, CNSA, ISRO, etc.)

* EUMETSAT

* European Union

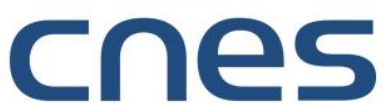

CENTRE NATIONAL

D'ÉTUDES SPATIALES

* European Space Agency

* Other space users

- Industry

* Science Laboratories 


\section{OBSERVATION}

\section{Protect the Earth by observing it from space}

When combined with in situ observations and numerical simulations, satellite observations help us understand, monitor and predict the state of the planet so that we can adapt to climate change, locally and globally.

$>$ Atmosphere/weather/climate

$>$ International Charter on Space and Major Disasters

$>$ Oceanography/Hydrology

$>$ Land surfaces

$>$ Earth/Environment

$>$ Solid Earth, geodesy, geomagnetism 


\section{Programmes being prepared or developed}

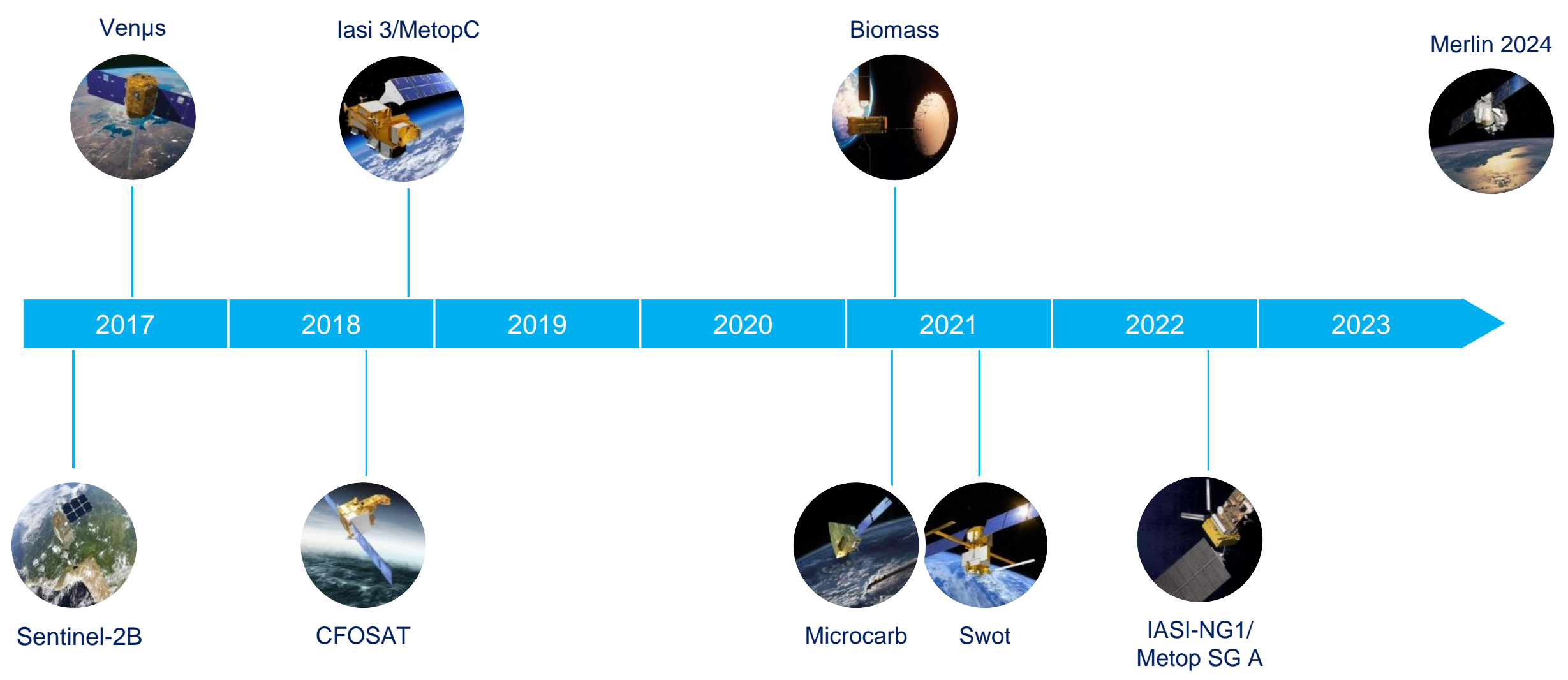


Based on IASI global heritage (system \& hardware) but with improved performances on radiometry, spectral resolution and absolute calibration ( $\mathrm{x} 2$ improvement).

With many hardware challenges : detectors, mechanisms, metrology, on board processing, active cooling ...

-CNES funds (partially) and deliver 3 FMs to Eumetsat

for Post EPS (Metop SG A)

-ADS in charge of IASI-NG development

-Contributions from UK on detectors (Selex) and Norway on laser source

(Kongsberg Defense and Aerospace)

-Phase C (detailed design) started begining of 2016

Instrument CDR mid 2019

Concept : Mertz Interferometer with field compensation

Qualified use of $\mathrm{KBr}$ for prism and beam-splitter

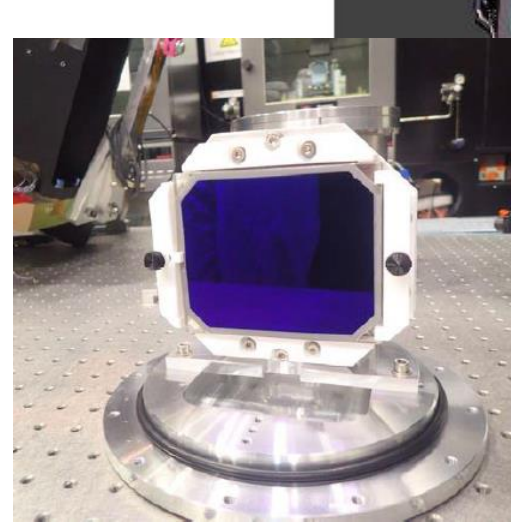

- Interferometer layout 


\section{Atmosphere/Climate}

\section{MicroCarb}

Studying atmospheric $\mathrm{CO}_{2}$ at the global scale

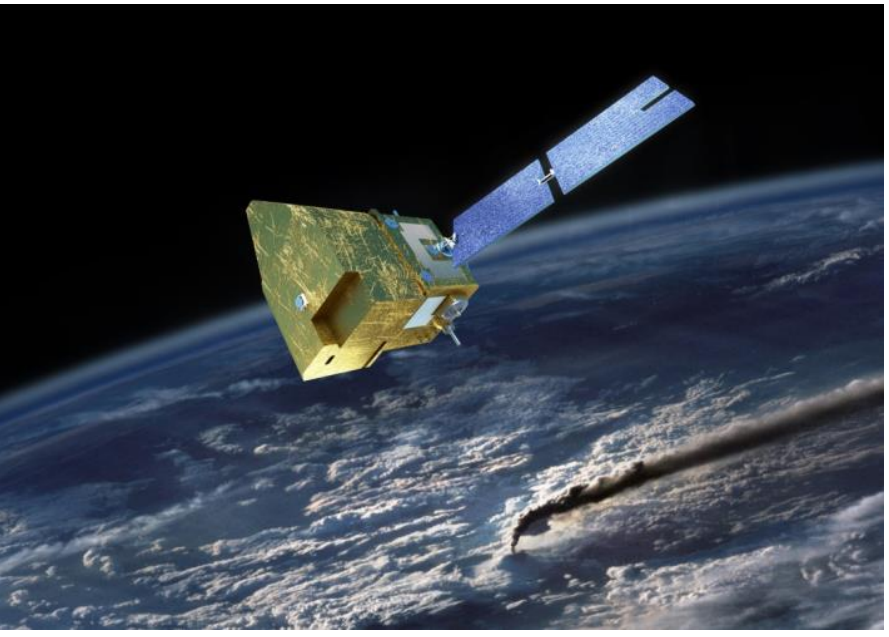

(c) CNES/O. Satler
The objective of MicroCarb is to create a global map of the sources and sinks of the main greenhouse gas, carbon dioxide $\left(\mathrm{CO}_{2}\right)$.

The mission aims to determine how the main carbon sinks of our planet the oceans and forests - function, and to map them.

At the same time, MicroCarb will measure how many tonnes of $\mathrm{CO}_{2}$ are emitted by all sources (especially human activities and vegetation) region by region.

CNES is the prime contractor for the system and the satellite, which are based on the Myriade platform; The payload consists of a passive spectrometer in the near infrared developed by ADS.

This project is being carried out by CNES in cooperation with the British Space Agency (UKSA) and in close partnership with the Laboratory of Climate and Environmental Sciences (LSCE), the Laboratory of Dynamic Meteorology (LMD) Of the Institut Pierre Simon Laplace (IPSL). 
MicroCarb will measure vertically integrated $\mathrm{CO}_{2}$ concentration :

to quantify $\mathrm{CO}_{2}$ surface fluxes at regional scales

- to identify and monitor global carbon sources and sinks

* Priority is given to precision on measurement (in ppm) rather than high spatial resolution or sampling

$=>$ Choice of a 4 bands (including OCO bands) compact echelle spectrometer design with ESA funded Sofradir SWIR NGP detector, passive cooling $(65 \mathrm{~kg} / 55 \mathrm{~W})$

The instrument concept is compatible with

The Myriades Evolution platform

Phase B (instrument) started beginning of 2016

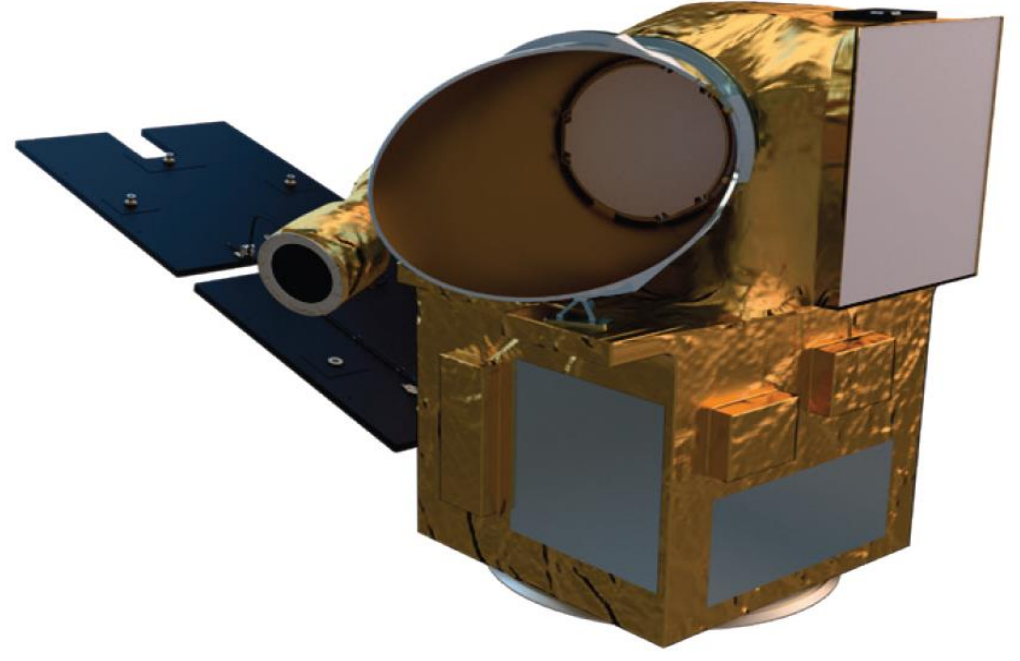

The MicroCarb instrument mounted on a Myriade platform 


\section{TRISHNA Scientific objectives}

cres ..

Proposed scientific objectives fo defined with the scientific comm

TIR imager with decametric reso

1) Ecosystem stress and

2) Coastal and inland w:
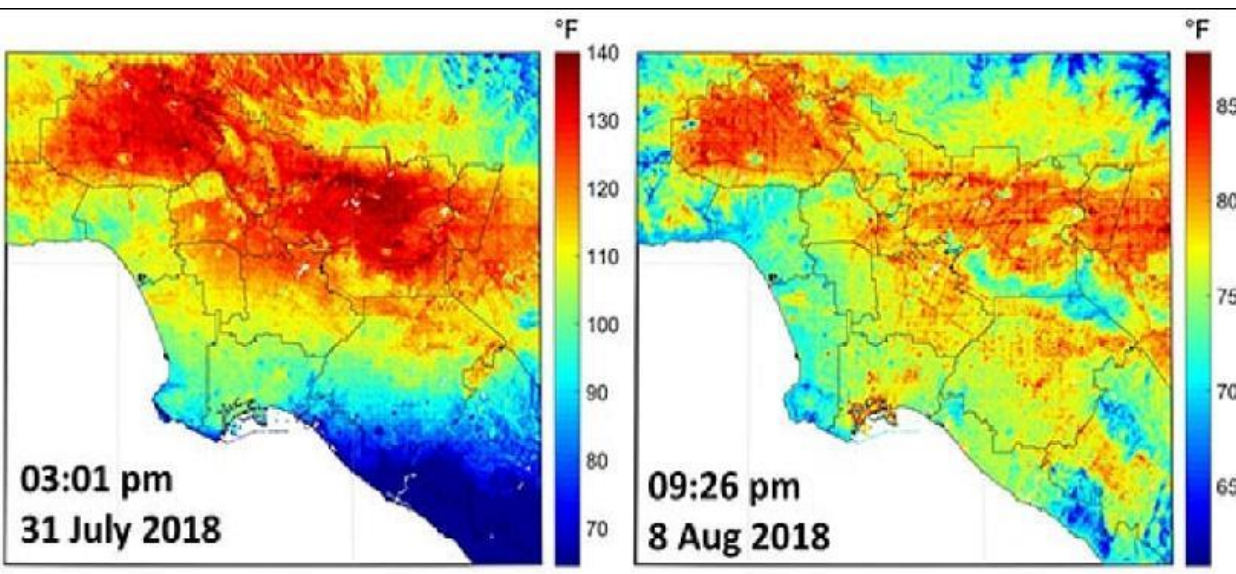

3) Urban

4) Solid Earth

5) Cryosphere

6) Atmosphere

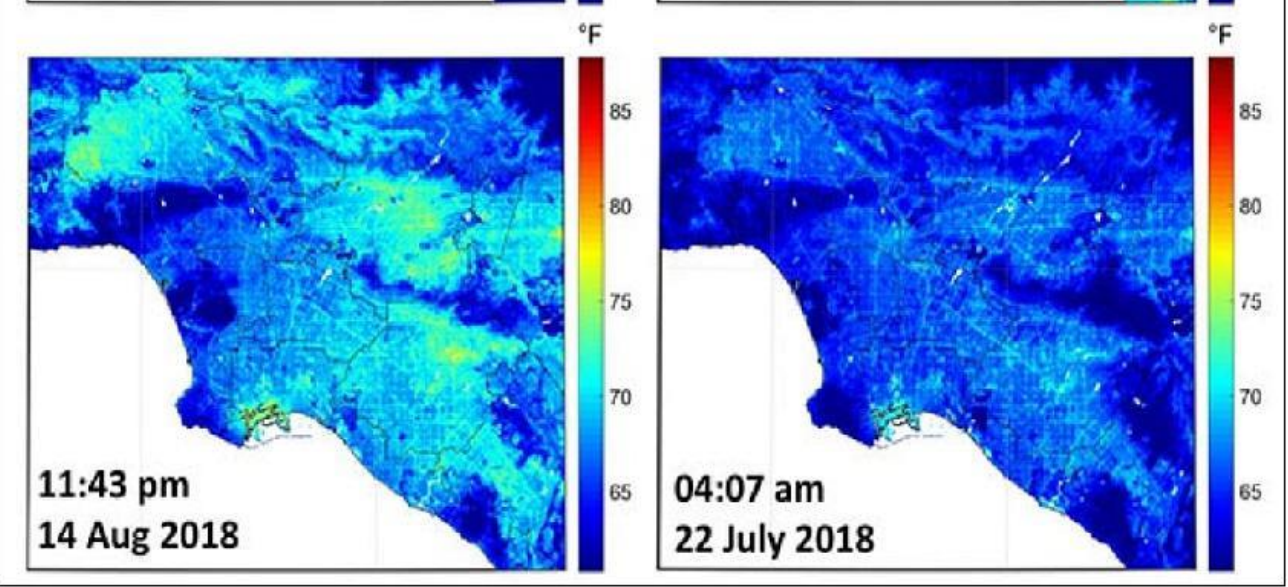

IRT product from ECOSTRESS captured from ISS (NASA/JPL-Caltech) 
Global coverage

Spatial resolution: $57 \mathrm{~m}$ (nadir)

Swath : +/- 34

Revisit: 3 days

Repeat 8 days $761 \mathrm{~km}$ orbit to avoid area systematicly affected by

Hotspot

Overpass time: $13: 00$ LST
Adapted IMS-2 bus used on Saral

- Sun tracking solar array

- High data rate telemetry

- Mass : $500 \mathrm{~kg}$

- Average power : 850W

Two instruments :

- VNIR/SWIR

- TIR

Dual launch on PSLV

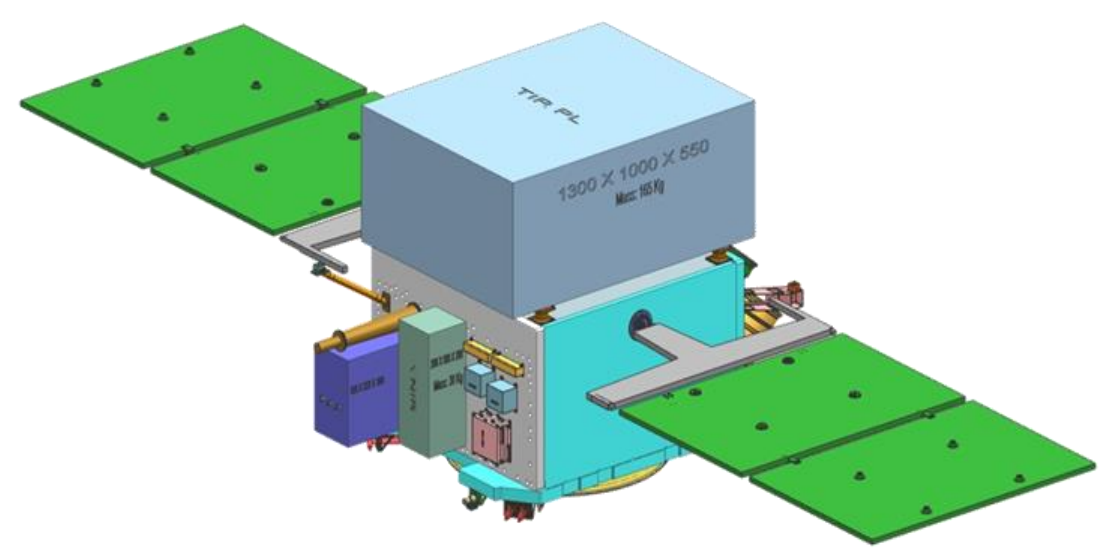




\begin{tabular}{|c|c|c|c|c|c|}
\hline $\begin{array}{l}\text { Band } \\
\text { name }\end{array}$ & Justification & $\begin{array}{l}\text { Wavelen } \\
\text { gth } \\
\text { center } \\
\text { (um) }\end{array}$ & $\begin{array}{l}\text { FWH } \\
\text { M } \\
(\mu \mathrm{m})\end{array}$ & $\begin{array}{c}\text { NeDT } \\
@ 300 \mathrm{~K} \\
\text { (K) }\end{array}$ & Tsat (K) \\
\hline TIR1 & \multirow{2}{*}{ Separation between LST and emissivity } & 8.6 & 0.35 & \multirow{4}{*}{0.3} & \multirow{4}{*}{400} \\
\hline TIR2 & & 9.1 & 0.35 & & \\
\hline TIR3 & \multirow{2}{*}{$\begin{array}{l}\text { High atmospheric transmission } \\
\text { High surface emissivity } \\
\text { Low variation of surface emissivity }\end{array}$} & 10.3 & 1.00 & & \\
\hline TIR4 & & 11.5 & 1.00 & & \\
\hline
\end{tabular}

\section{Two concepts studied}

- Starer or Scanner

- MCT cooled detector

Mass : $165 \mathrm{~kg}$ Average power : $245 \mathrm{~W}$

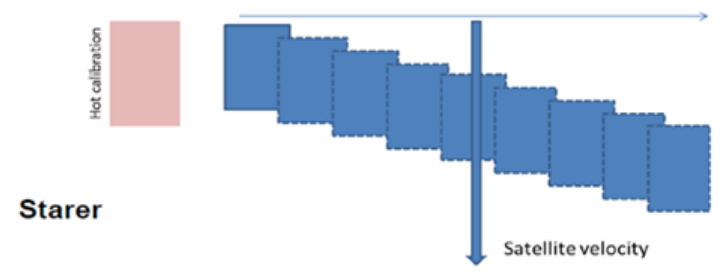

Scanner

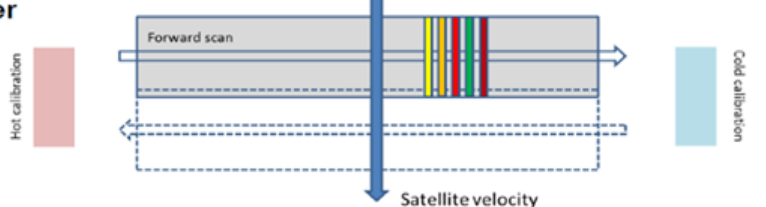




\begin{tabular}{|c|c|c|c|c|c|c|}
\hline $\begin{array}{l}\text { Band } \\
\text { name }\end{array}$ & Purpose & $\begin{array}{l}\text { Wavele } \\
\text { ngth } \\
\text { center } \\
(\mathbf{n m})\end{array}$ & $\begin{array}{c}\mathrm{FWH} \\
\mathrm{M} \\
(\mathrm{nm})\end{array}$ & $\underset{\substack{\left.\operatorname{Lm} / \mathrm{m}^{2} / \mathrm{sr} / \\
\mu \mathrm{m}\right)}}{\operatorname{Lin}}$ & $\begin{array}{l}\text { SNR } \\
@ \text { L } \\
\text { min }\end{array}$ & $\begin{array}{c}\text { Lsat } \\
\left(\mathrm{W} / \mathrm{m}^{2} / \mathrm{sr} /\right. \\
\mu \mathrm{m})\end{array}$ \\
\hline Blue & $\begin{array}{l}\text { Cloud detection for atmospheric } \\
\text { correction }\end{array}$ & 485 & 70 & 40 & 100 & 500 \\
\hline Green & $\begin{array}{l}\text { Green peak, sensitive to total } \\
\text { chlorophyll and sediment for coastal } \\
\text { applications }\end{array}$ & 555 & 70 & 30 & 100 & 500 \\
\hline Red & Maximum chlorophyll absorption & 650 & 60 & 20 & 100 & 500 \\
\hline NIR & $\begin{array}{l}\text { NIR plateau, sensitive to total } \\
\text { chlorophyll, biomass, LAI and protein; } \\
\text { retrieval of aerosol load and type }\end{array}$ & 860 & 30 & 15 & 100 & 300 \\
\hline $\begin{array}{l}\text { CIRRUS } \\
\text { (TBC) }\end{array}$ & $\begin{array}{c}\text { Detection of thin cirrus for atmospheric } \\
\text { correction }\end{array}$ & 1380 & 30 & 0.06 & 100 & 30 \\
\hline SWIR & for snow/ice/cloud separation & 1610 & 150 & 0.40 & 100 & 60 \\
\hline
\end{tabular}

Mass : $25 \mathrm{~kg}$ Average power : $90 \mathrm{~W}$

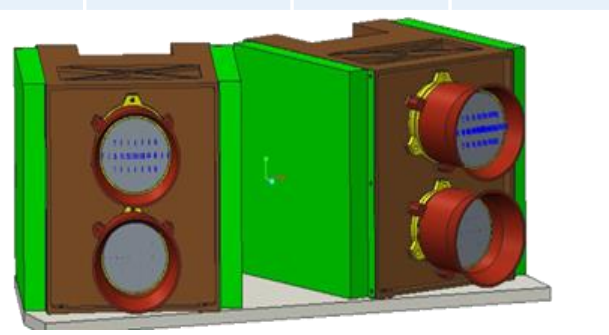




\section{System : ISRO/CNES}

Satellite : ISRO

- Bus : ISRO

- Thermal Infrared Instrument : CNES

- VNIR/SWIR Instrument : ISRO

- Payload Data Processing/Telemetry : ISRO TBC

Control Ground Segment : ISRO

Mission Ground segment : ISRO/CNES

- Duplicated processing centers

Launcher : ISRO end 2024_begining 2025 
Some phase 0 studies have been conducted on Lidar altimetry missions since 2008. They have produced two earth explorer proposals (2010) with strong participation of various french labs (Z-Earth for high accuray DEM and LEAF for vegetation measurement) and support from industry. But they were not selected neither proposed again recently. Some specific R\&T studies have also been conducted on technics inspired from Microwave altimetry to fight against the main drawbacks of these kind of mission (low coverage, low pulse repetition frequency...). Waiting for Icesat 2 products !

During a workshop organised by CNES in 2011, two specific critical technologies related to detection (APD from CEA-Leti) and control of wavelength of the Lidar (DROPO from ONERA) were identified and have given rise to several $R \& T$ activities. These two technologies have progressively been included in different Lidar breadboards to test their performances and increase their TRL level : Coupling of APD with COWI Dial Lidar (LMD) dedicated to measurement of CO2 and use of DROPO in a breadboard of a multi-wavelength Lidar for multi-species measurement (WaVILL Lidar IPLS/ONERA funded by ANR).

MESCAL is being studied with NASA as a CALIPSO/EarthCare follow-on mission dedicated to aerosols and clouds. On CNES side we are ready to start a phase A next year.

On a technological point of view CNES/ONERA have recently started very disruptive R\&Ts on dual comb spectroscopy that seem to be very promising to improve perfomance measurement and access some vertical resolution. A phase 0 study (SCALE) has been decided to assess the performance of such a concept. This new concept will be presented at ICSO 2018. 


\section{- esa}

\section{ESA-DEVELOPED EARTH OBSERVATION MISSIONS}

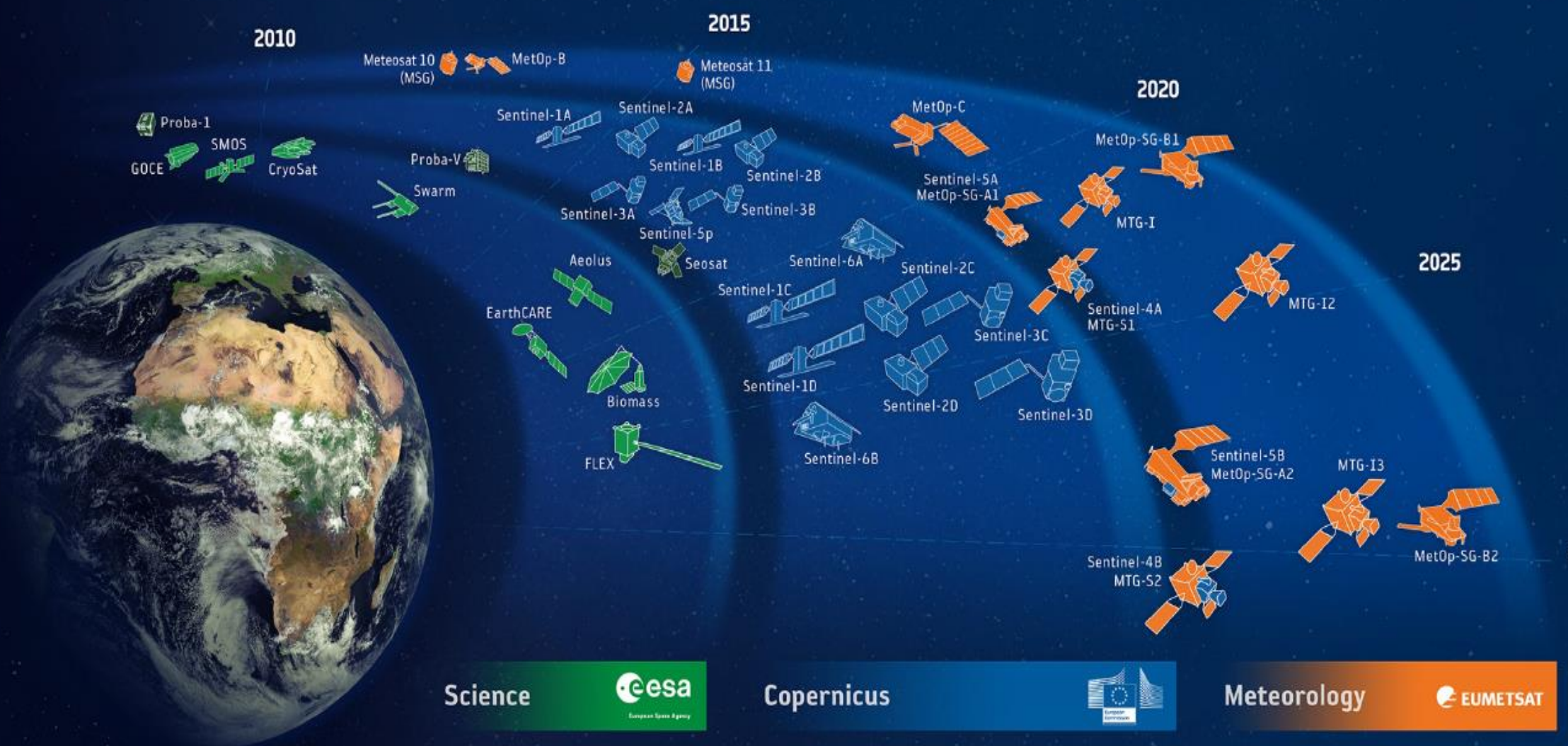


- Development of methods based on ground and extra-terrestrial targets for on orbit calibration of remote sensors:

Ocean sites

(molecular

scattering)
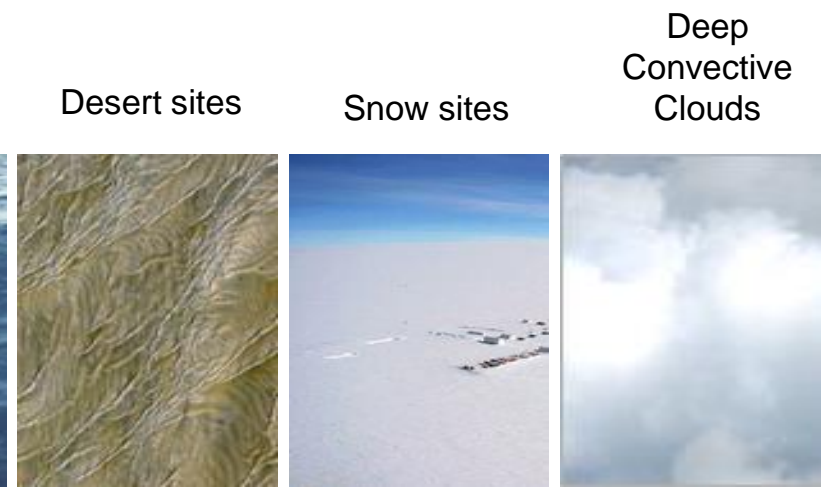
Ocean sites
(sunglint)

The moon

Stars

Instrumented

sites

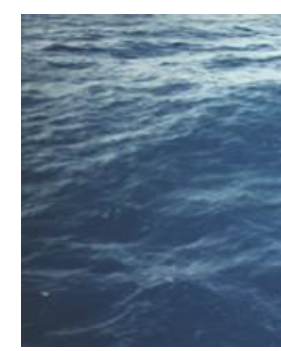

Absolute Multi-temporal Multi-spectral Cross-calibration
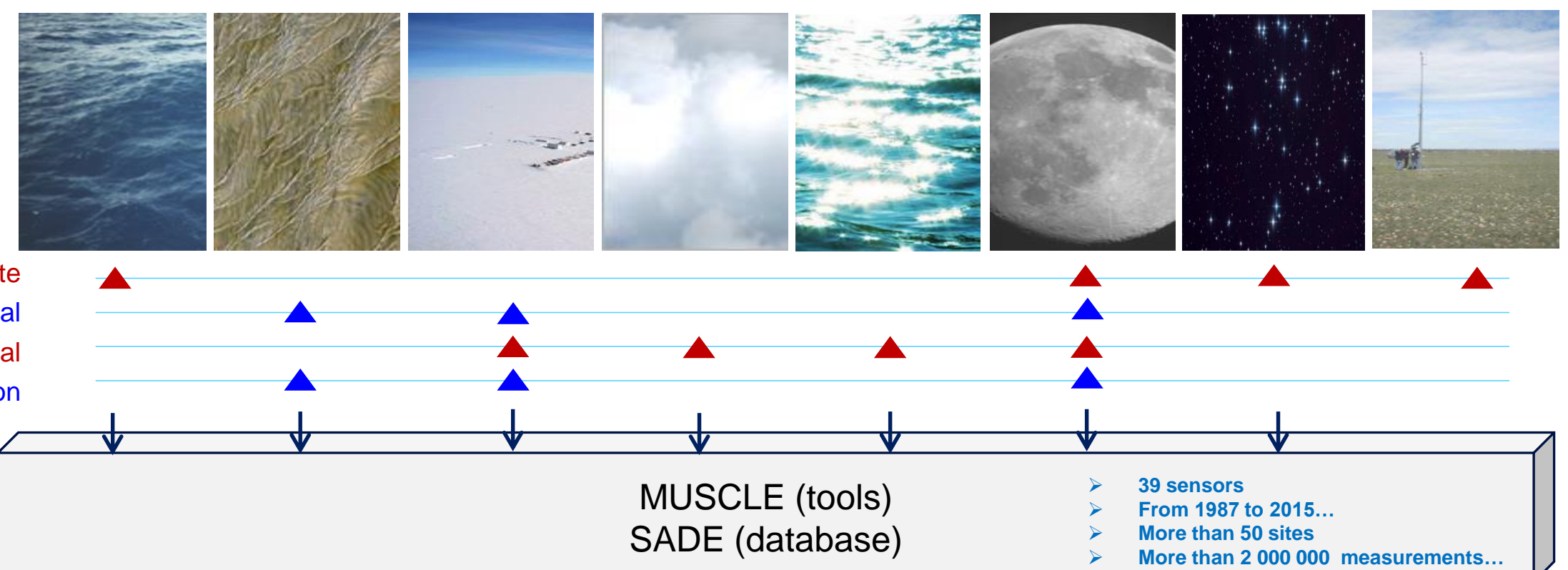

.
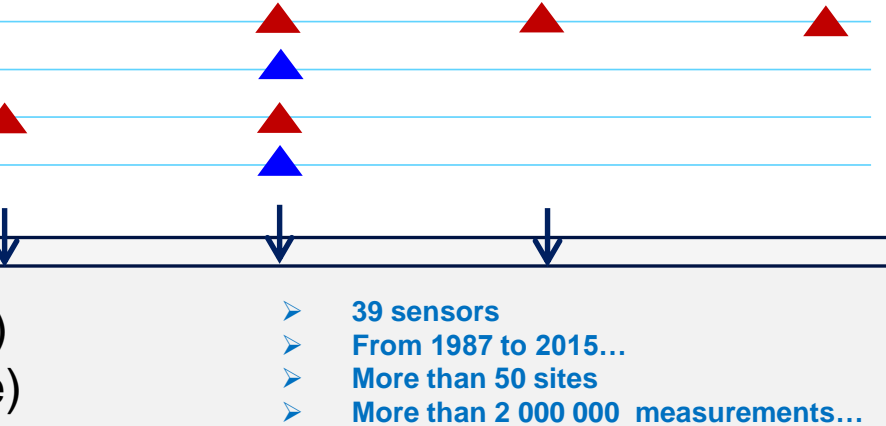

$\Rightarrow$ MUSCLE-NG under development: opening to partners 
C CNES skills on vicarious calibration internationally recognized:

ESA: SENTINEL-2 and SENTINEL-3

口 EUMETSAT: 3MI

- NASA: calibration data and results exchange (LANDSAT-8, MODIS, SNPP VIIRS)

I NSPO: THEOS

- Airbus Defense and Space: SPOT6, SPOT7

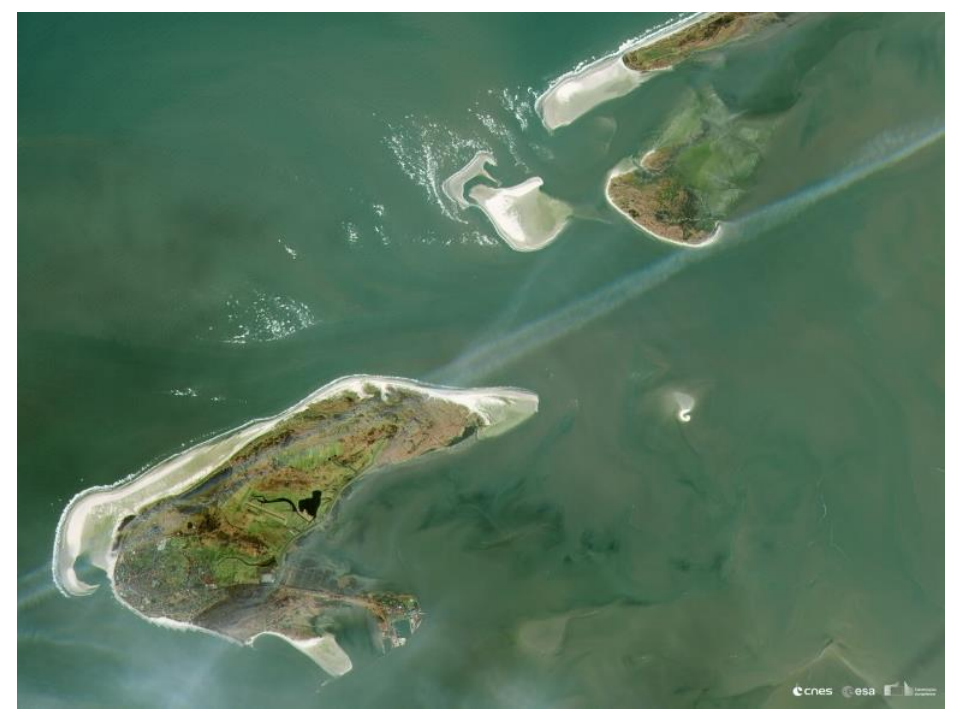




\section{The Calibration Pole}

- Sounders cross-calibration: IASI-A, IASI-B, AIRS and CRIS

- IASI is the reference for TIR sounding
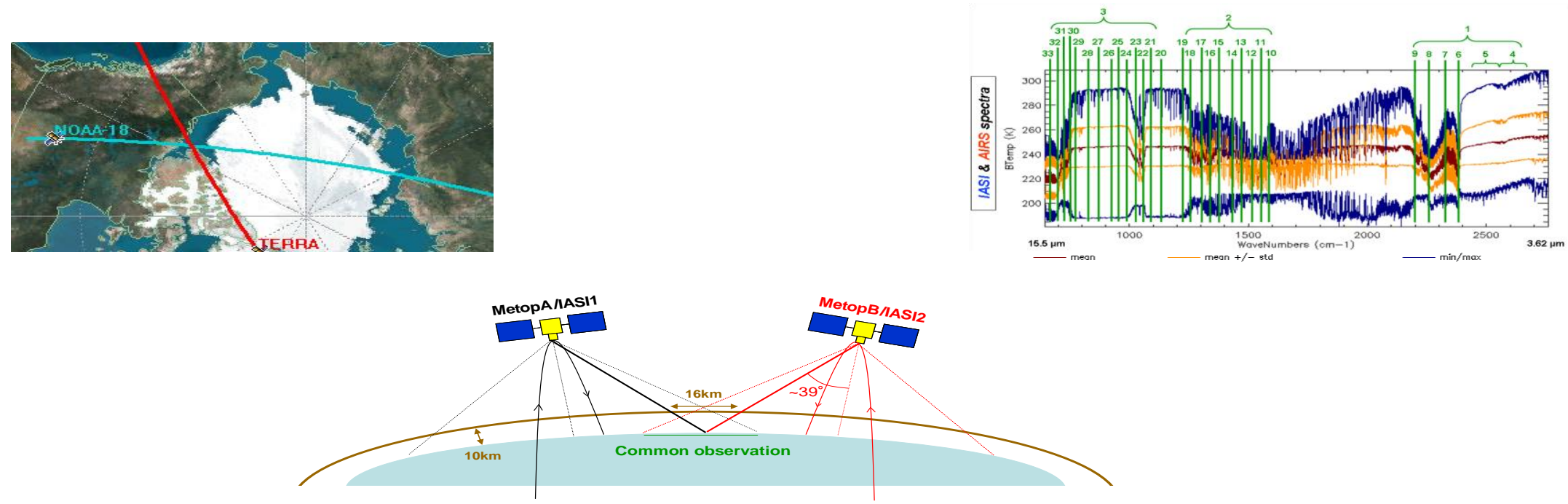

- Sharing results with NASA and NOAA within GSICS 


\section{Pleiades (currently in operation)}

A dual-use optical Earth observation system

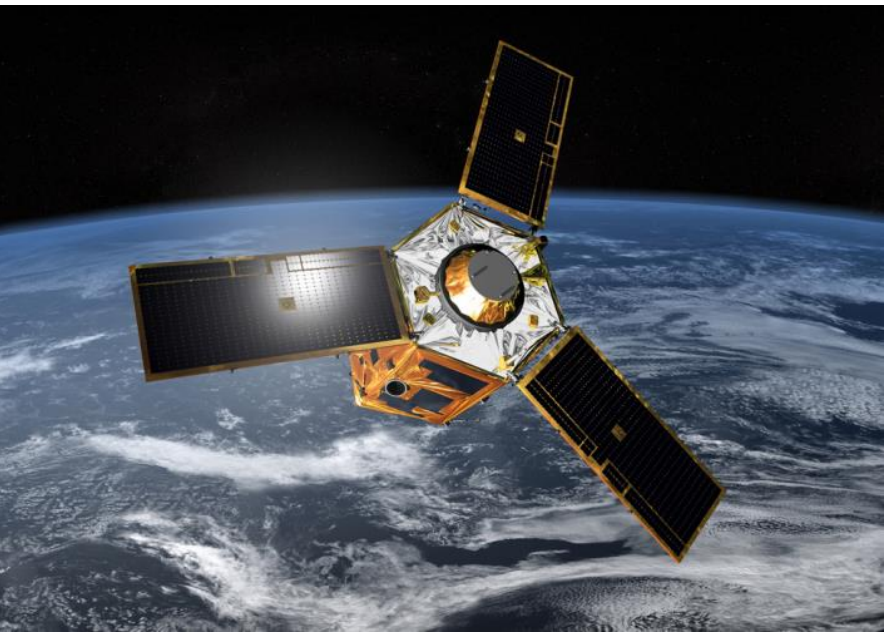

High resolution and very high manoeuvrability that can meet the needs of numerous users.

Programme developed with Austria, Belgium, Spain and Sweden.

Pleiades 1A was launched on 17 December 2011

Pleiades 1B was launched on 2 December 2012 


\section{DEFENCE}

\section{Imagery intelligence}

\section{CSO MUSIS}

Multinational space imagery system for surveillance, reconnaissance and observation

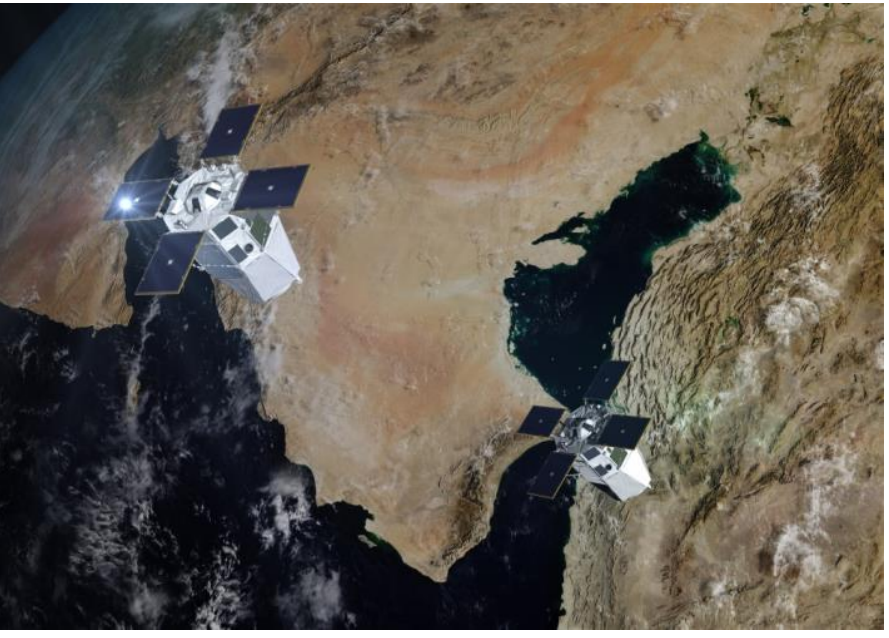

๑ CNES/Mira Productions
The optical space component of the future European MUSIS system (MUltinational Space-based Imaging System for surveillance, reconnaissance and observation) is being developed by France, with the DGA having delegated authority for the space component to CNES.

From 2019, CSO will follow on from Helios 2, bringing improved resolution, images in colour and second-generation infrared, as well as greater agility.

Three satellites will be placed in orbit: two on a high orbit for reconnaissance and one on a low orbit for identification.

The third satellite has been built under a cooperation agreement with Germany. 


\section{Demonstrators}

CNES implements a dynamic policy of demonstrator projects for dual purposes in coordination with the Ministry of Defence.

It aims to achieve a significant improvement in performance without increasing risks, while maintaining France's technical excellence and leadership and at the same time paying due regard to the cost of programmes.

Example for high resolution Earth Observation = OTOS (Observation de la Terre Optique Super résolue). 
OTOS is a CNES technology program

preparing next generation of earth observation satellite

$\leftrightarrow$ OTOS is the frame of technological developments,

in particular optical developments and breadboards dedicated to active optics.

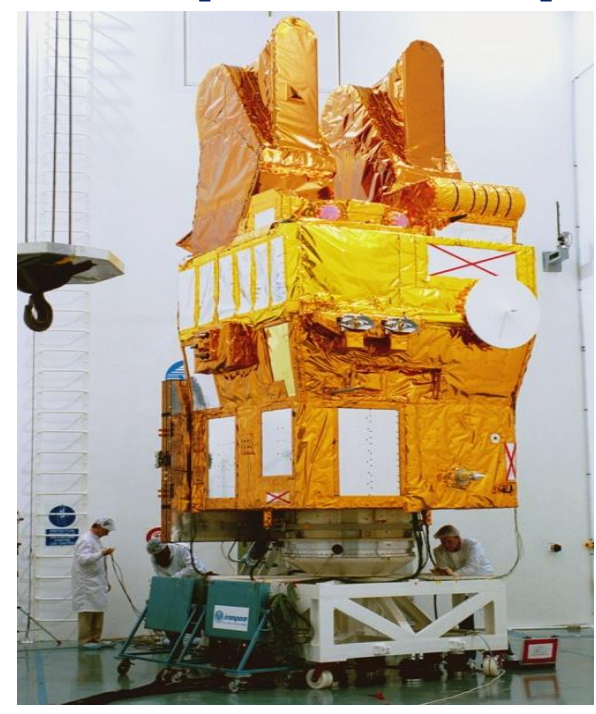

2002 : SPOT5 $2 \mathrm{~m} 50$

$3000 \mathrm{~kg} / 2500 \mathrm{~W}$

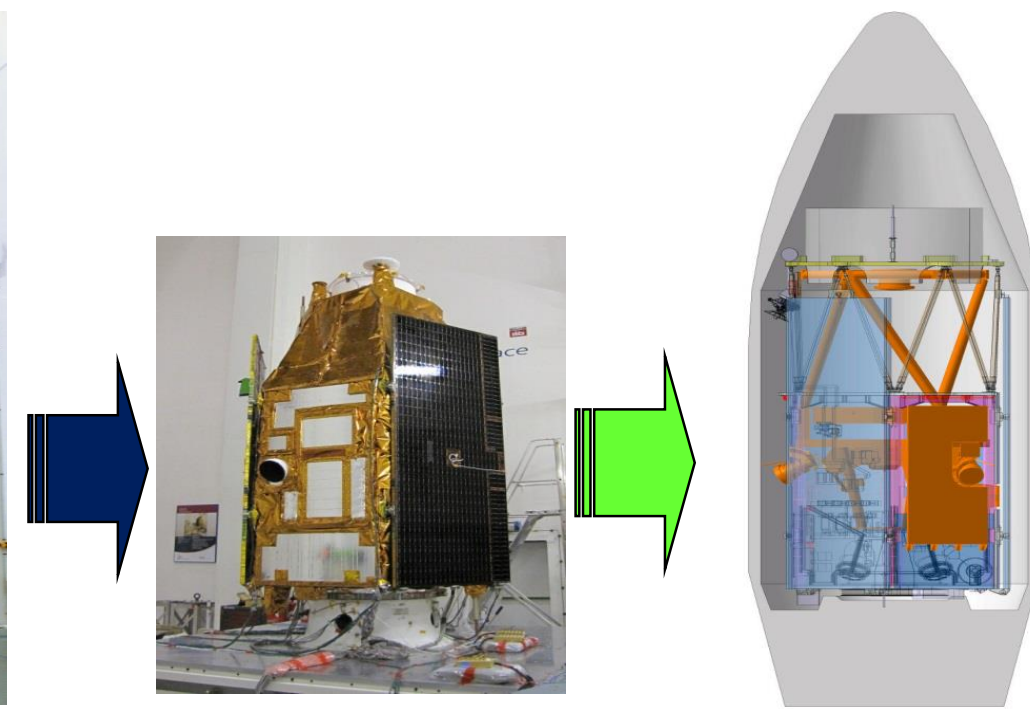

2011 : PLEIADES $70 \mathrm{~cm}$ $1000 \mathrm{~kg} / 1500 \mathrm{~W}$
2021/22: OTOS $30 \mathrm{~cm}$

$1500 \mathrm{~kg} / 2000 \mathrm{~W}$ 


\section{OTOS Main optical drivers}

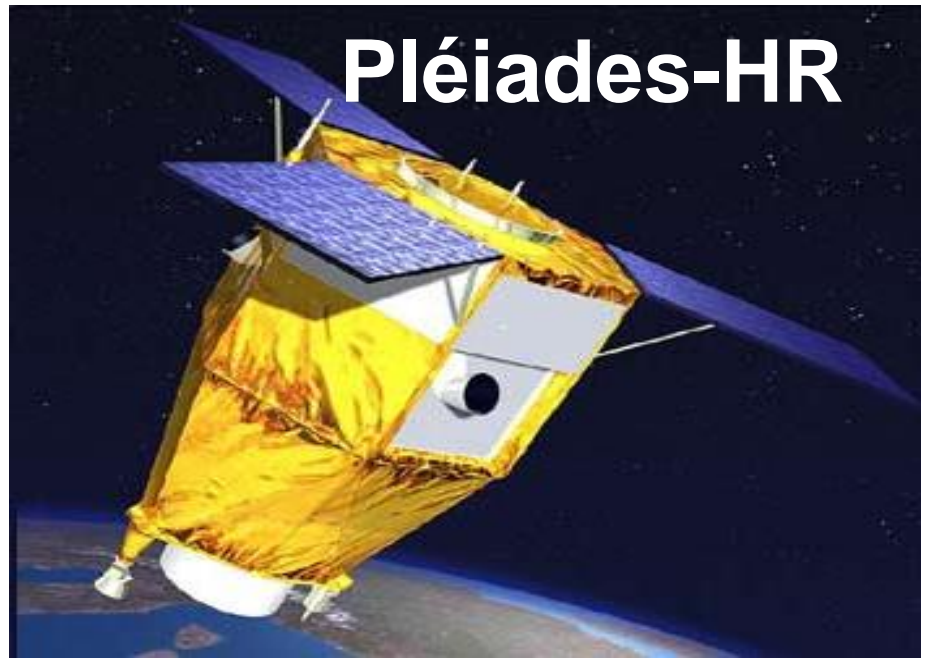

Panchromatic pixel size : $70 \mathrm{~cm}$ (nadir),

Low Earth Orbit : 700 km, swath width : $21 \mathrm{~km}$ (1,7 degrees),

Pupil dimension : $0.65 \mathrm{~m}$,

Telescope f-number : F/20,

Panchromatic and multispectral imaging sensor.

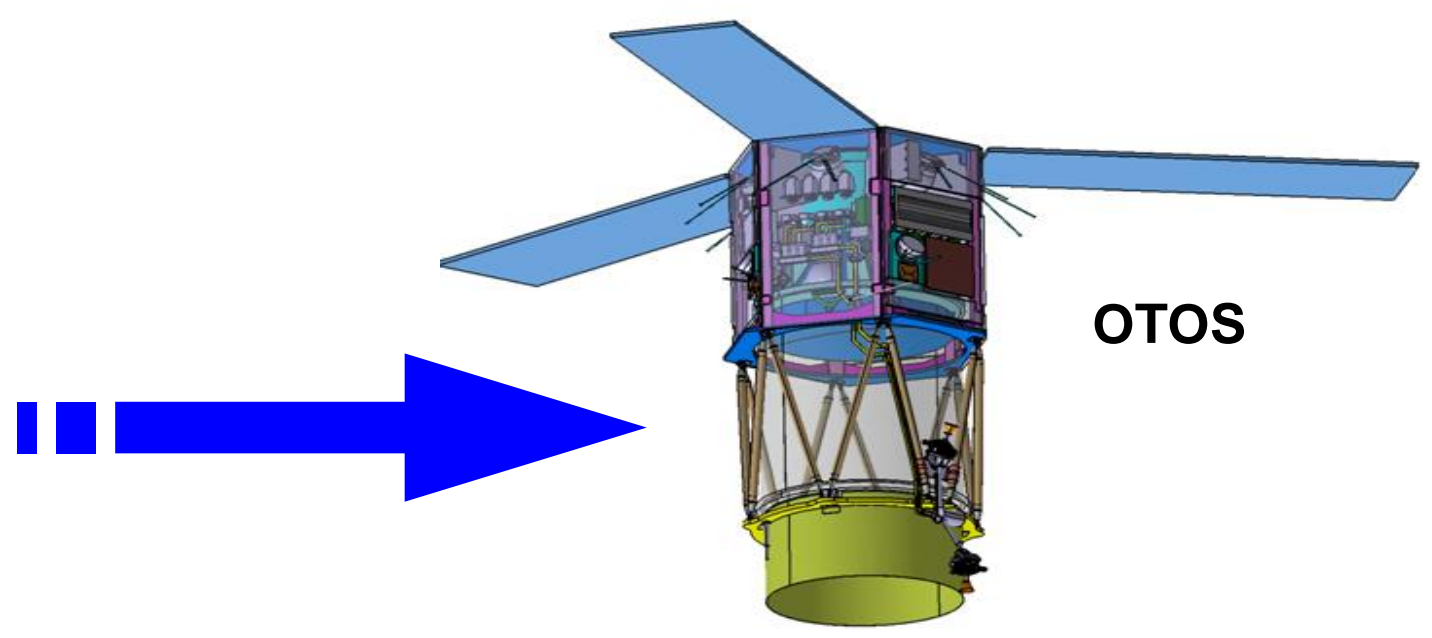

Panchromatic pixel size : $30 \mathrm{~cm}$ (nadir), Low Earth Orbit : 700 km, swath width : $15 \mathrm{~km}$ (1,2 degrees), Pupil dimension : $1.5 \mathrm{~m}$,

Telescope f-number : F/20,

Panchromatic and multispectral imaging sensor, Spacecraft compatible with Vega launch vehicle. 


\section{OTOS : Main technical challenges}

\section{Telescope (TANGO) :}

Airbus Defence \& Space and Thales Alenia Space France developments :

New concepts of extremely lightweight optical mirror

> Metrology systems (device and algorithm): shack-hartmann, focal plane phase retrieval

$>$ Deformable mirrors

$>$ Mirror positioning mechanisms

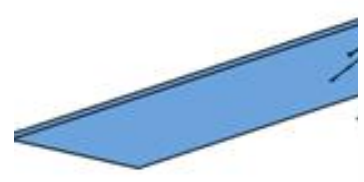

Full scale telescope demonstrator of a large active instrument (TRL 5 achieved on critical technologies).

Developed by Thales Alenia Space France with a validation in 2019

Focal Plane :

High performance TDI CCD development including video electronic, box, filters

CMOS TDI XS (6 bands) based on STM foundry
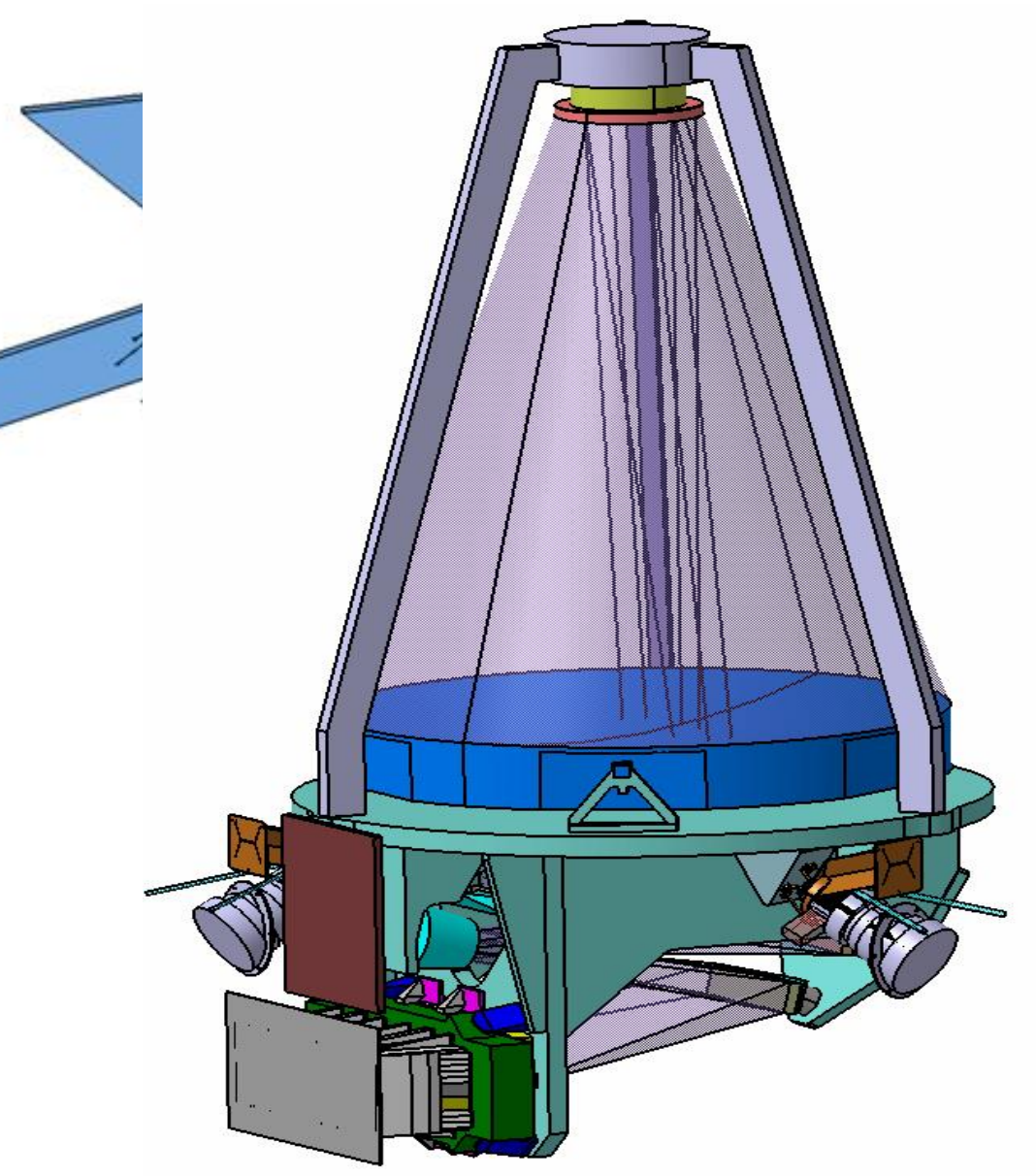


\section{OTOS : Main technical challenges}

$c$

- cnes ..

THALES ThalesAlenia THALES SESO

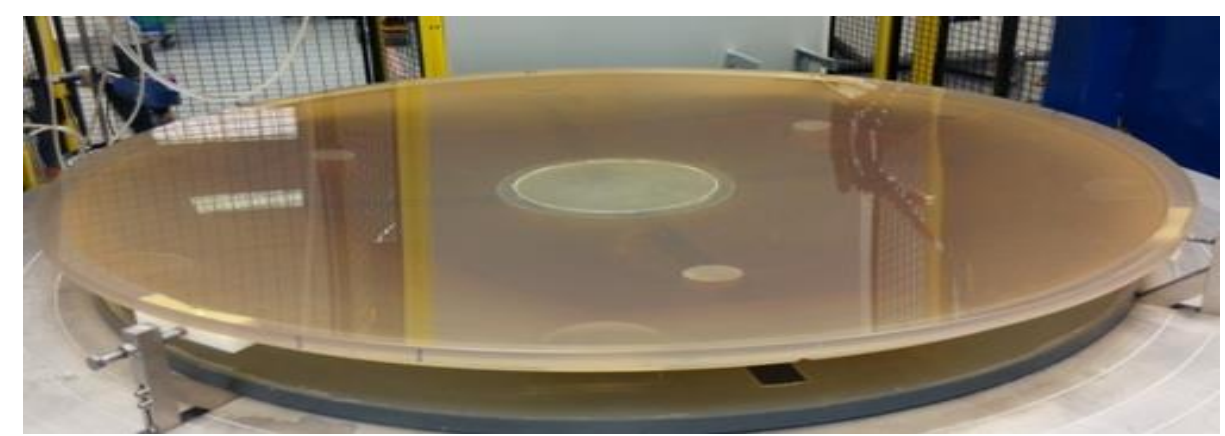

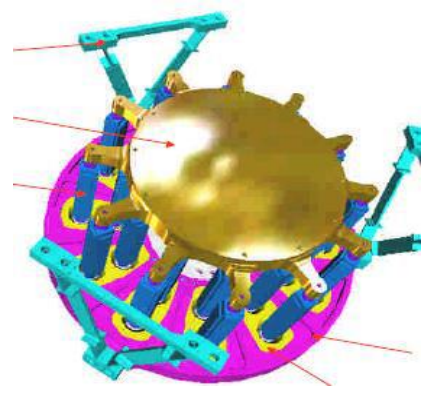

ThalesAlenia

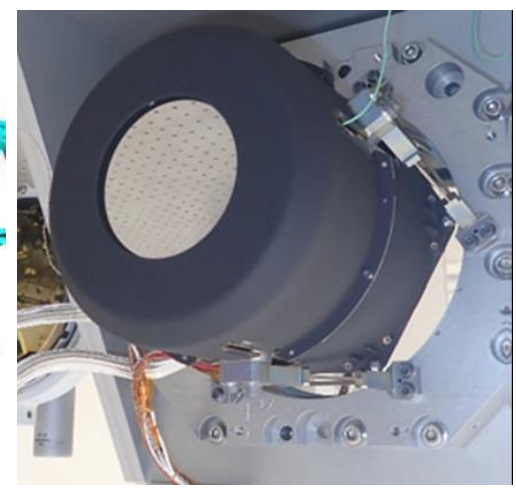

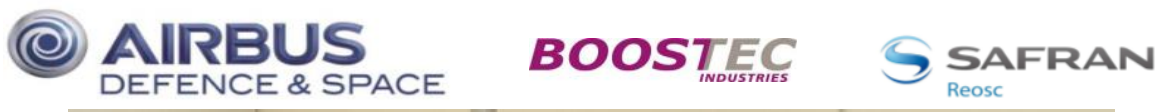

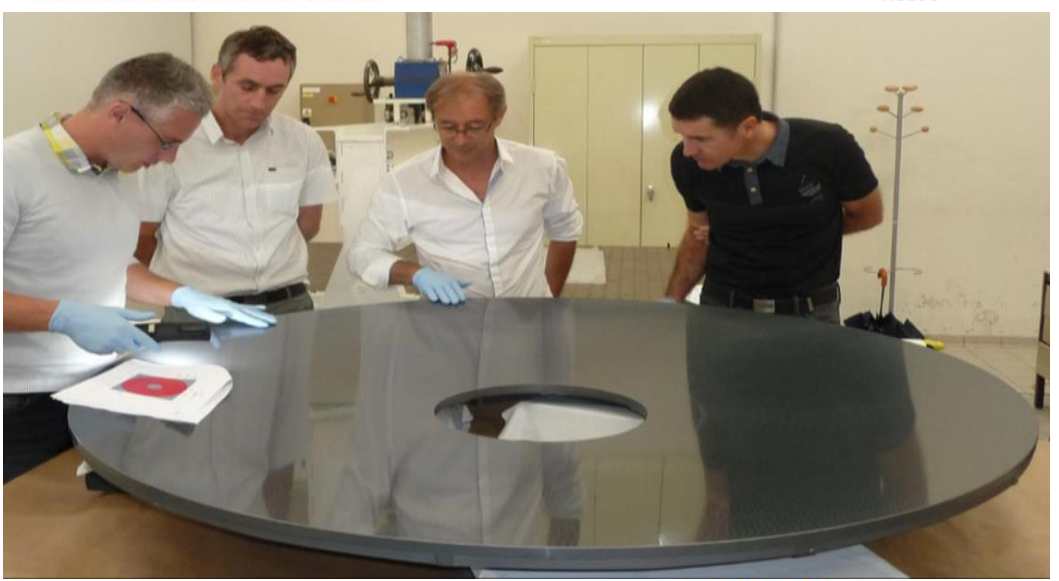

Optical

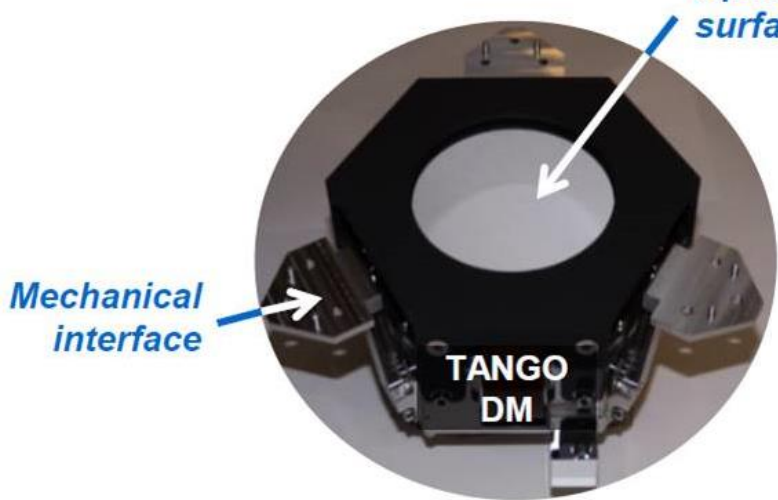

Pilas

arıaneGroup 


\section{SCIENCE}

\section{Explore space, to answer the following questions:}

* How was our solar system formed and how does it work?

* What are the fundamental laws of the Universe?

* How was the Universe formed, and what is its structure?

* What conditions are necessary for planets to form and life to emerge?

* What are the latest developments concerning manned exploration of the solar system?

$>\quad$ Astronomy and astrophysics

$>$ Solar system

$>\quad$ Sun, heliosphere, magnetospheres

$>$ Fundamental physics

$>$ Exobiology

$>\quad$ Life sciences \& materials sciences and in microgravity 


\section{Programmes being prepared or developed}

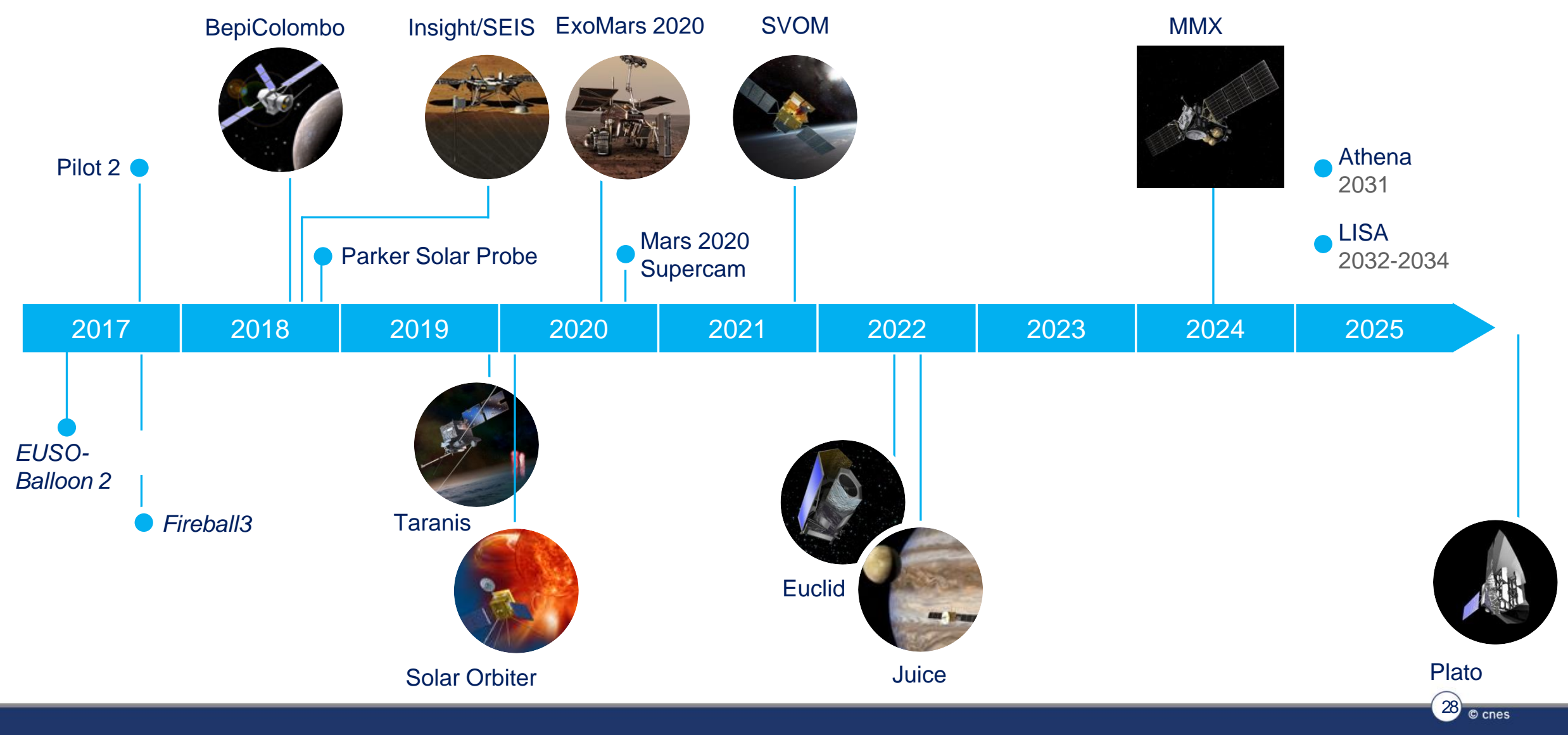




\section{SCIENCE}

\section{Astronomy/Astrophysics}

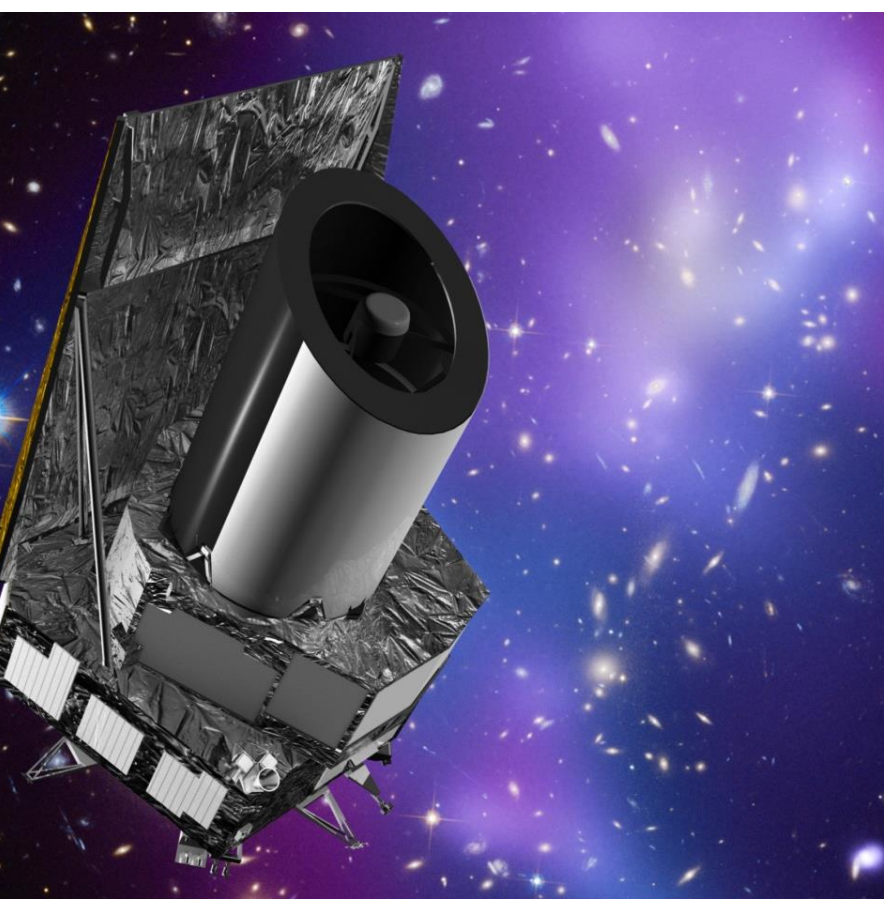

\section{Euclid}

In search of dark energy

Euclid will map several hundred million galaxies in a large part of the universe. Its goal is to analyse their apparent distortions caused by dark matter, and to help scientists understand the nature of the mysterious dark energy that makes up around $70 \%$ of the Universe.

The project is part of ESA's 2015-2025 Cosmic Vision programme. France initiated this project through CNES, the CNRS and the CEA. A consortium of European laboratories and institutes will provide the instruments and the data-processing system.

\section{Launch planned for 2022}




\section{Telescope and scientific instruments}

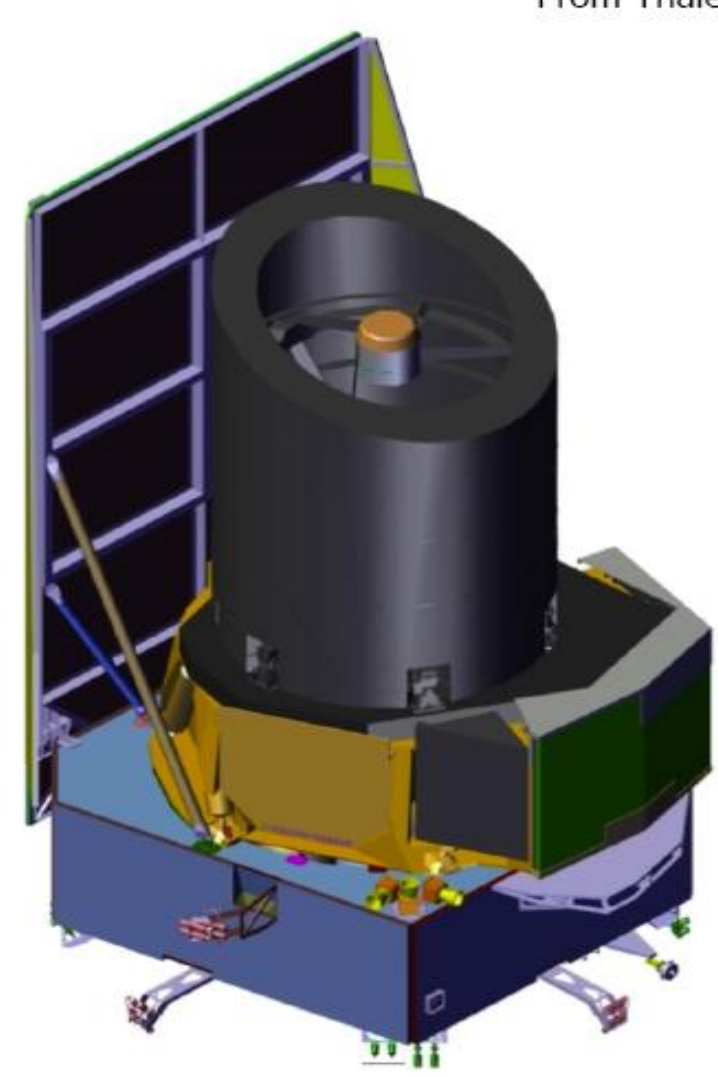

- Télescope 1,2 m: FoV: $0.54 \mathrm{deg}^{2}$

- Miror in Silicon Carbide= ultra-stable: Temp.: -150 deg. Stability +:- 0.05 deg.

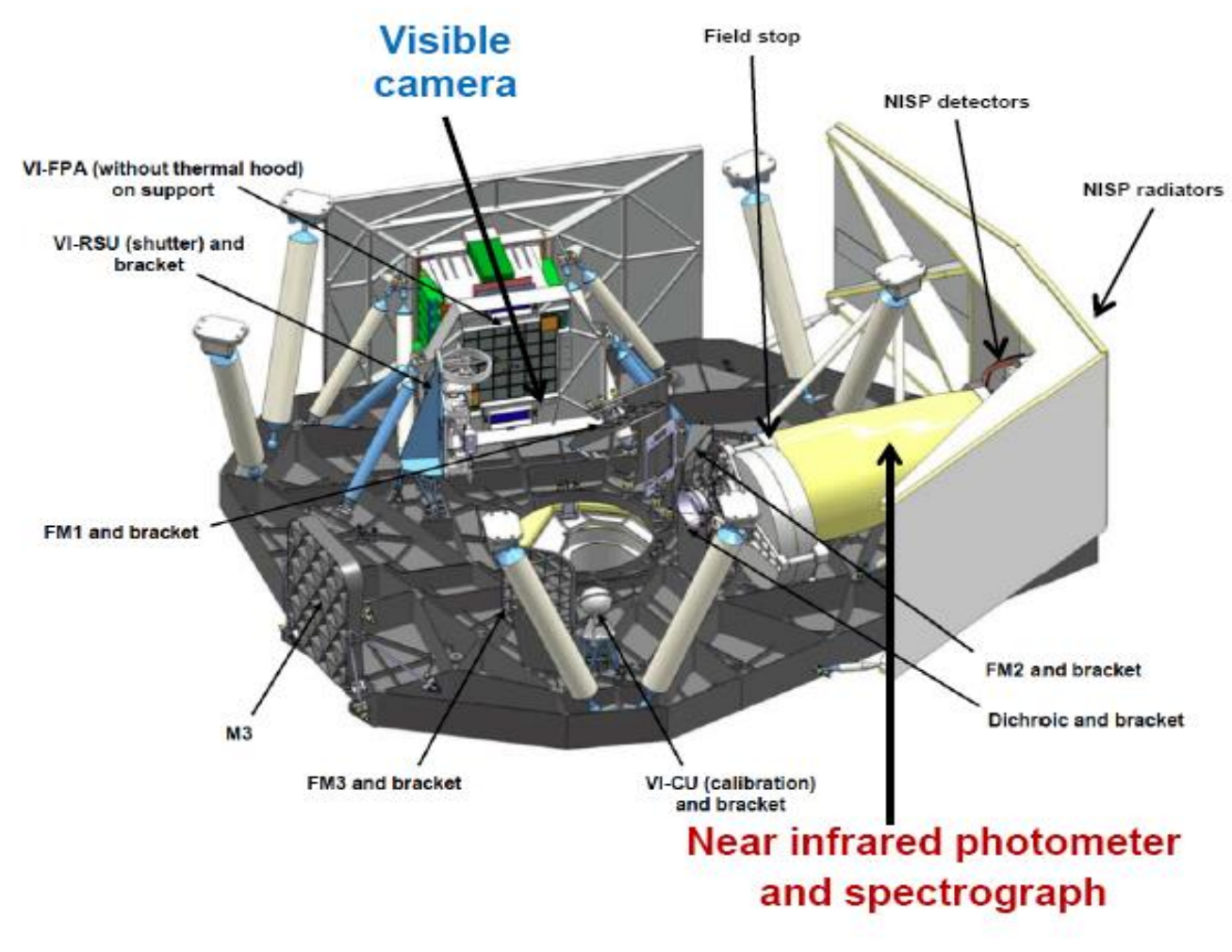

Common visible and infrared field of view $=0.54 \mathrm{deg}^{2}$ 


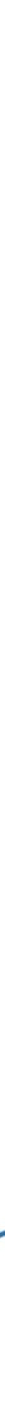




\section{ATHENA}

Studying the hot and energetic Universe

- ATHENA (Advanced Telescope for High-ENergy Astrophy: is the future European space-based X-ray observatory. It consists of two instruments: the X-IFU (Integral Field Unit), very high resolution spectrometer, and the medium spectre resolution WFI (Wide Field Imager).

The scientific objective of the mission is especially to answ three questions: In what kind of (very large-scale) structure does matter assemble itself in the Universe? How do black holes behave? and What is their role in the evolution of the Universe?

$\checkmark$ ESA is in charge of the mission, the satellite and of coordinating operations. Two scientific consortia will provic the instruments and the data processing. France is participating in ATHENA via its contribution to ESA's mandatory science programme for the mission, satellite an ground segment aspects. CNES, within the X-IFU Consort is the prime contractor of the whole system and responsibl the X-IFU instrument.

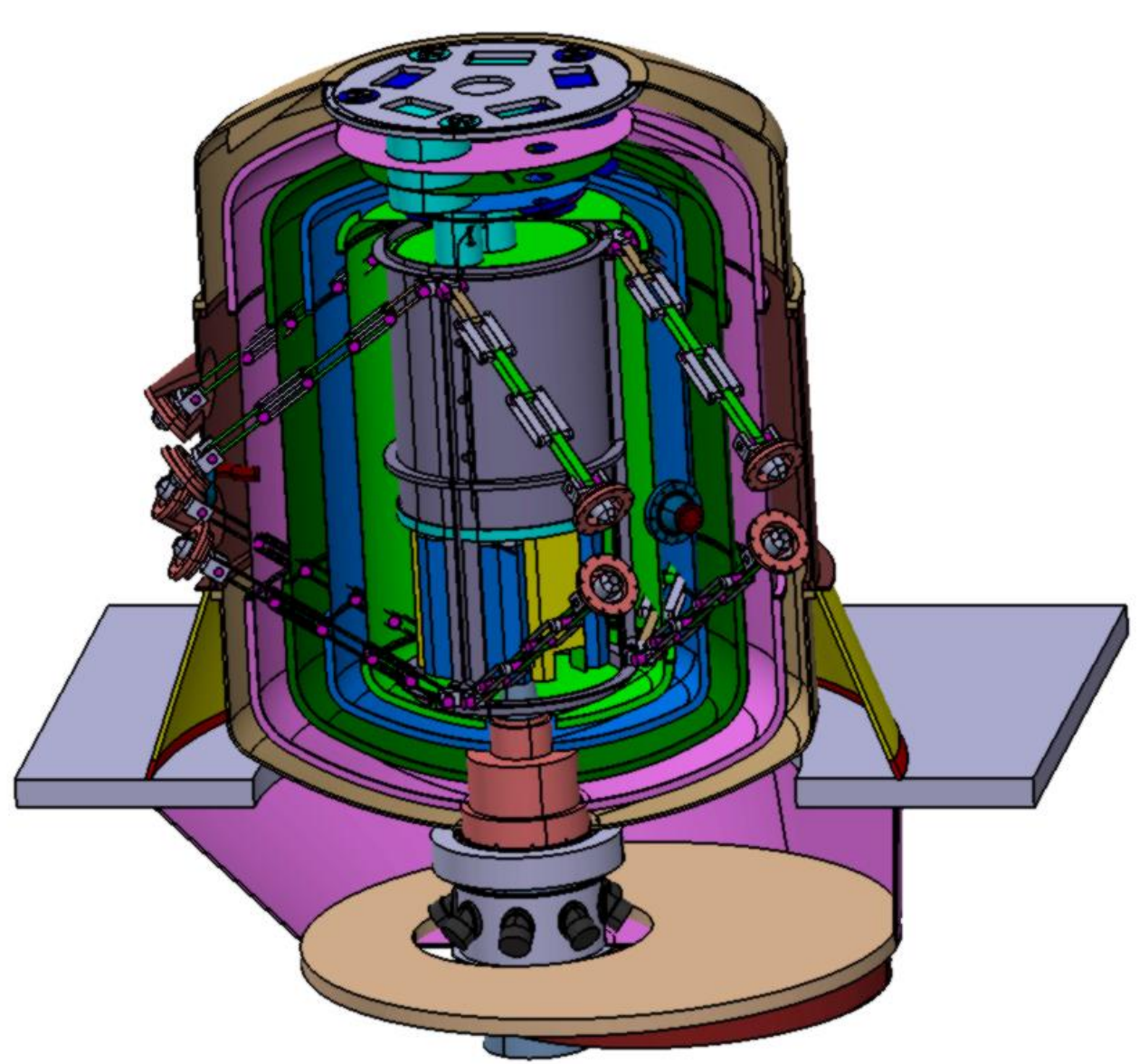




\section{Phebus / Bepi Colombo}

PHEBUS spectrometer (Probing Hermean Exosphere by Ultraviolet Spectroscopy)

French PI instrument developped by LATMOS (France)

EUV-FUV spectrometer (55 to $315 \mathrm{~nm}+404$ \& $422 \mathrm{~nm}$ )

with japanese detectors

Phebus delivered and integrated on MPO (launch October 2018)

Entrance baffle
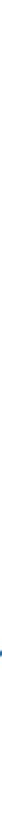


\section{SCIENCE}

\section{Solar system}

\section{Juice}

Ability of Jupiter's frozen moons to support life

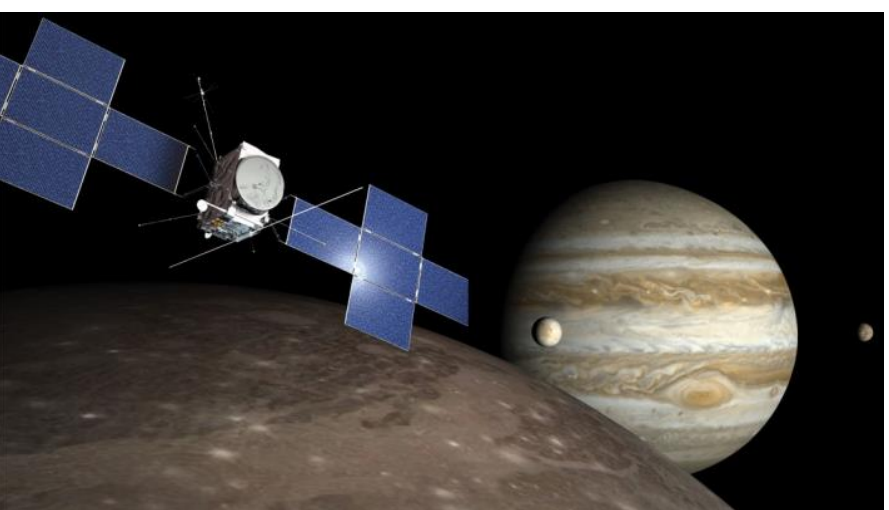

๑ AIRBUS DEFENCE SPACE
JUICE (Jupiter Icy Moons Explorer) is an ESA mission

Its aim is to study the giant planet, its magnetosphere, its frozen moons (Ganymede, Europa, Callisto) and their subglacial oceans.

CNES, together with French and European scientific laboratories, will supply the MAJIS (Moons and Jupiter Imaging Spectrometer) instrument and contribute to several others. 


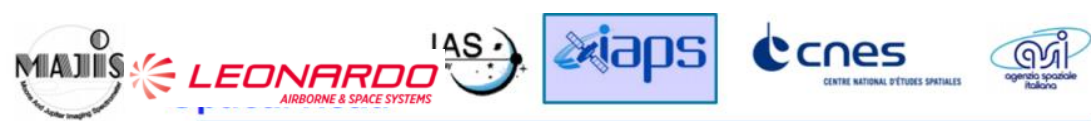

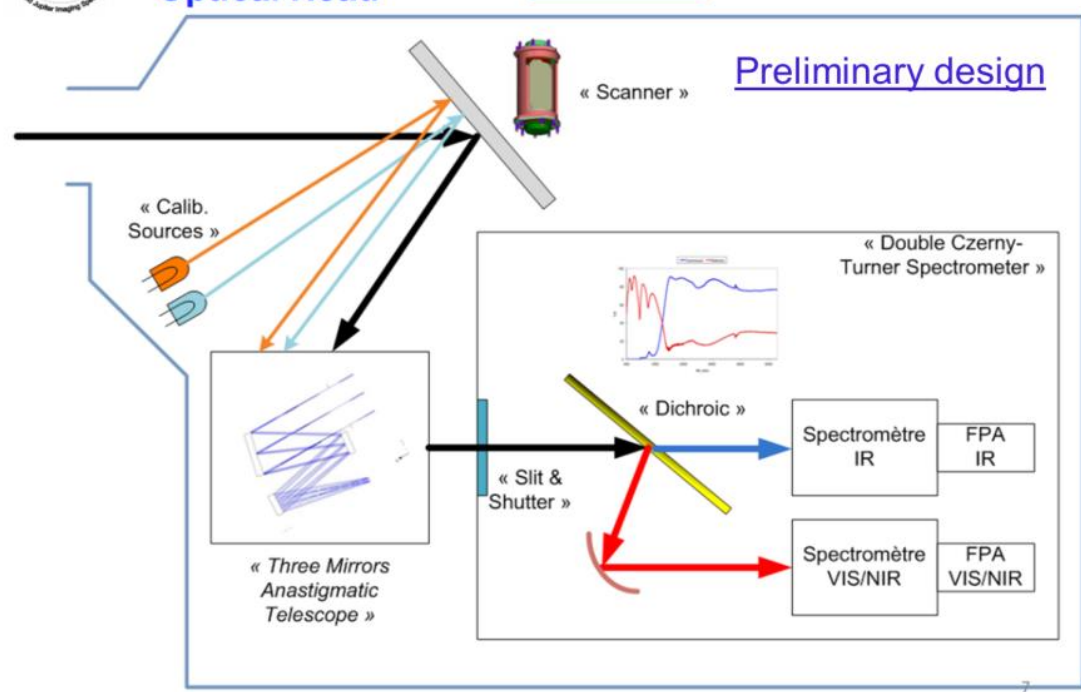

$2,25-5,54 \mu \mathrm{m}$

$0,5-2,35 \mu \mathrm{m}$
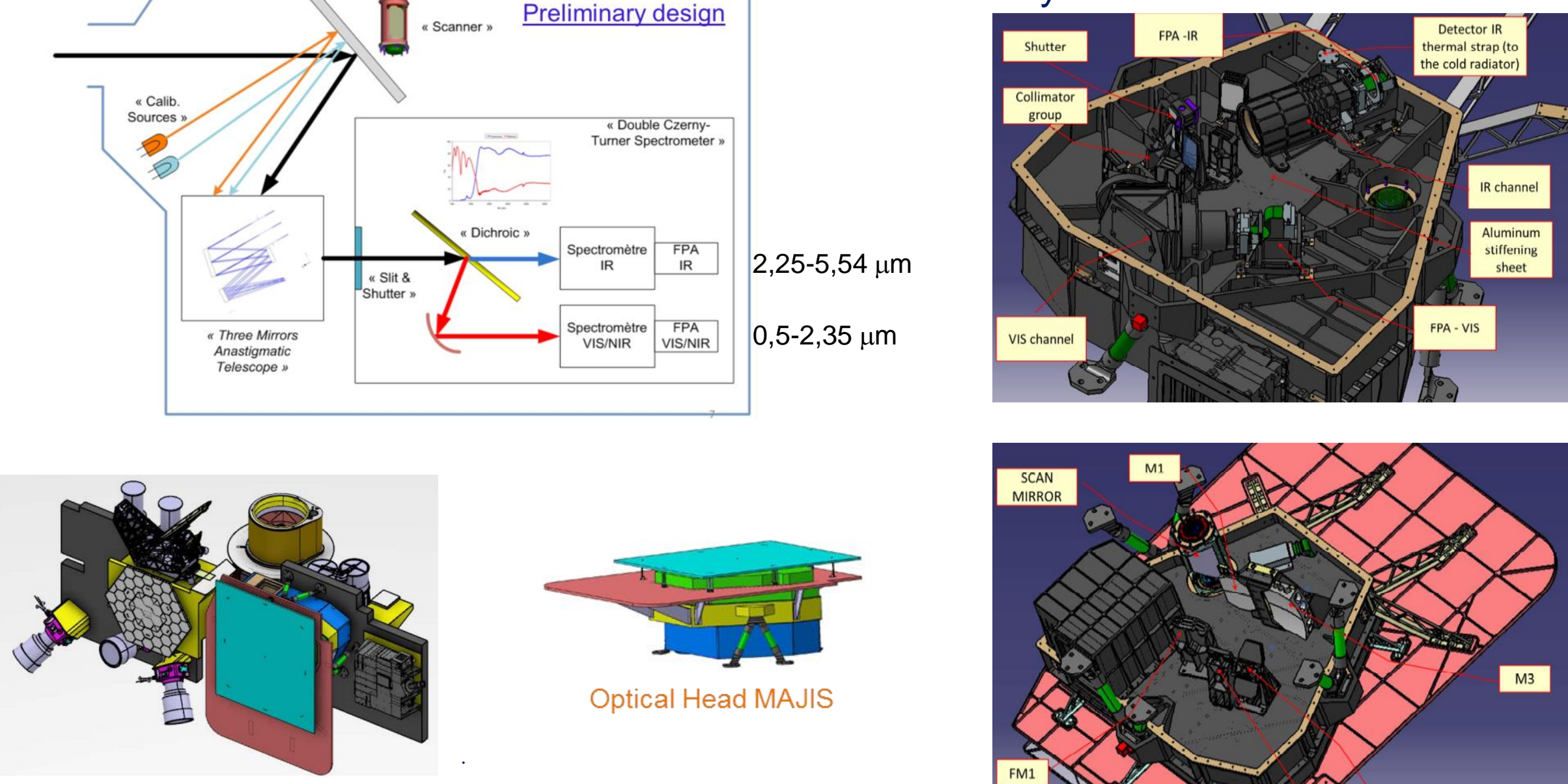

SCIENCE

Solar system

Q

cnes ...
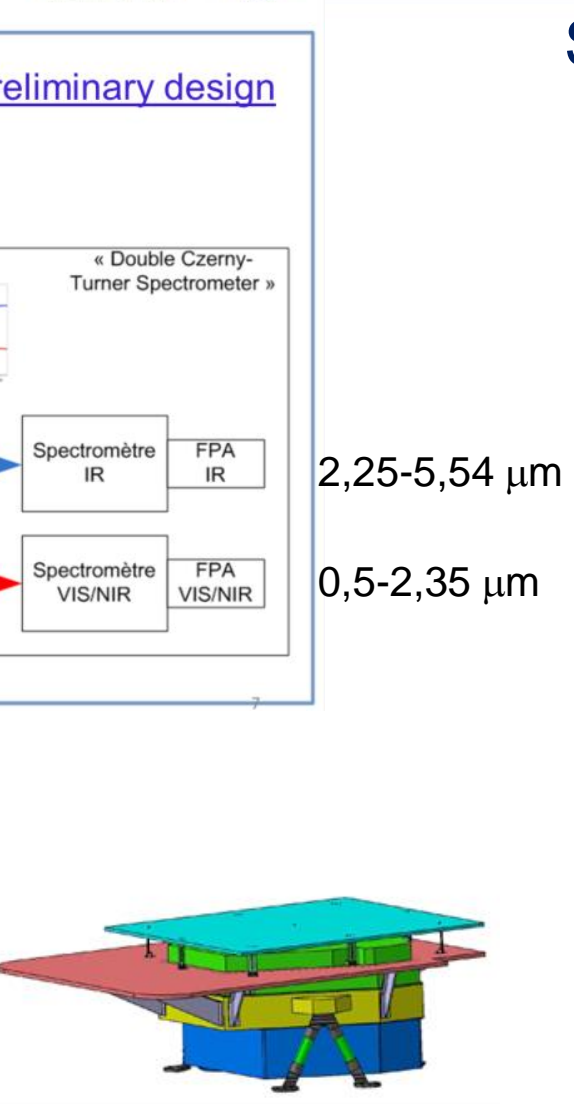

Optical Head MAJIS

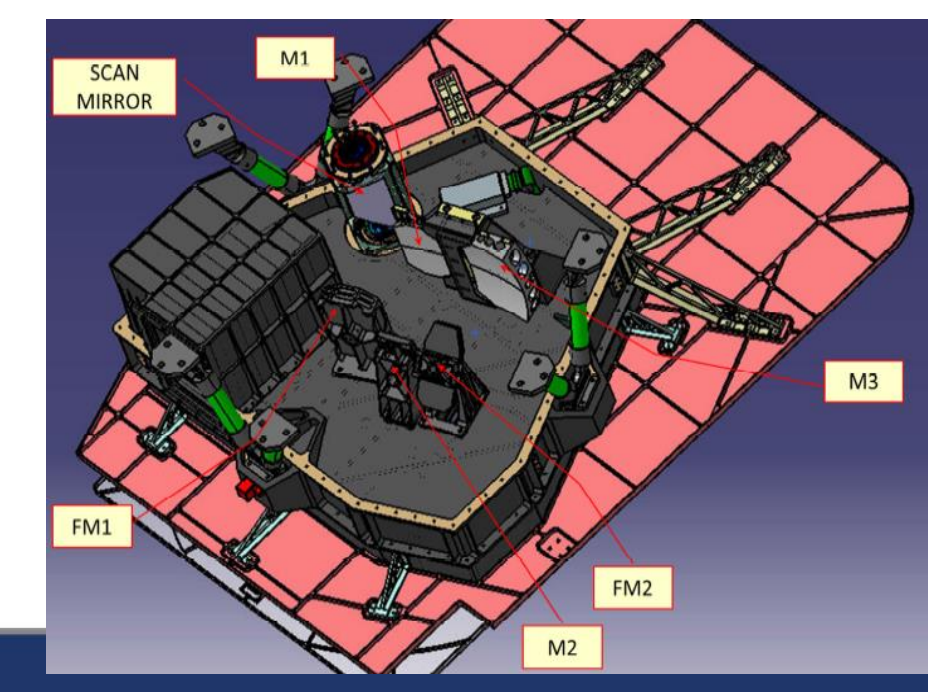




\section{The french contribution:}
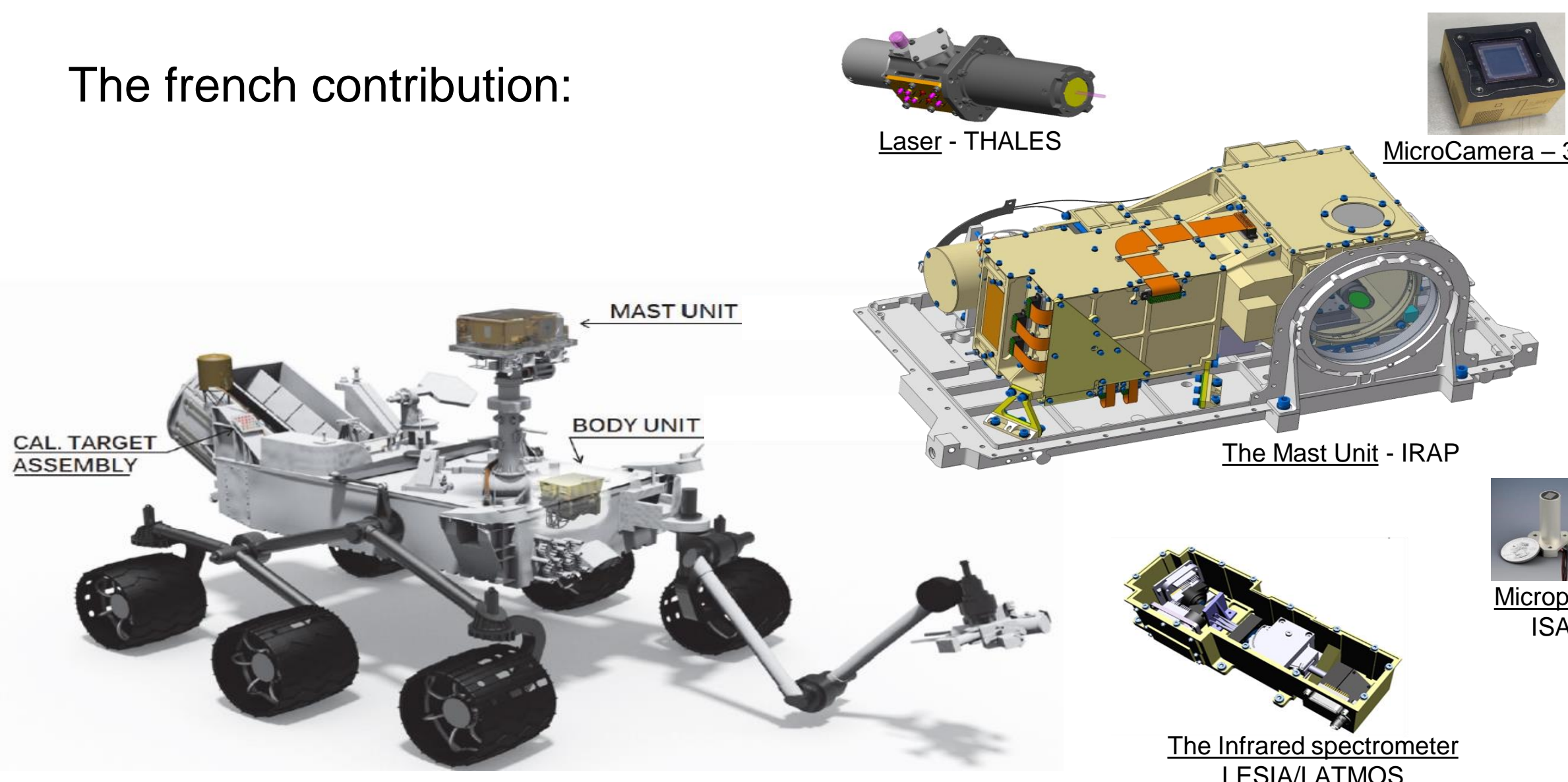

Laser - THALES

MicroCamera - 3D+
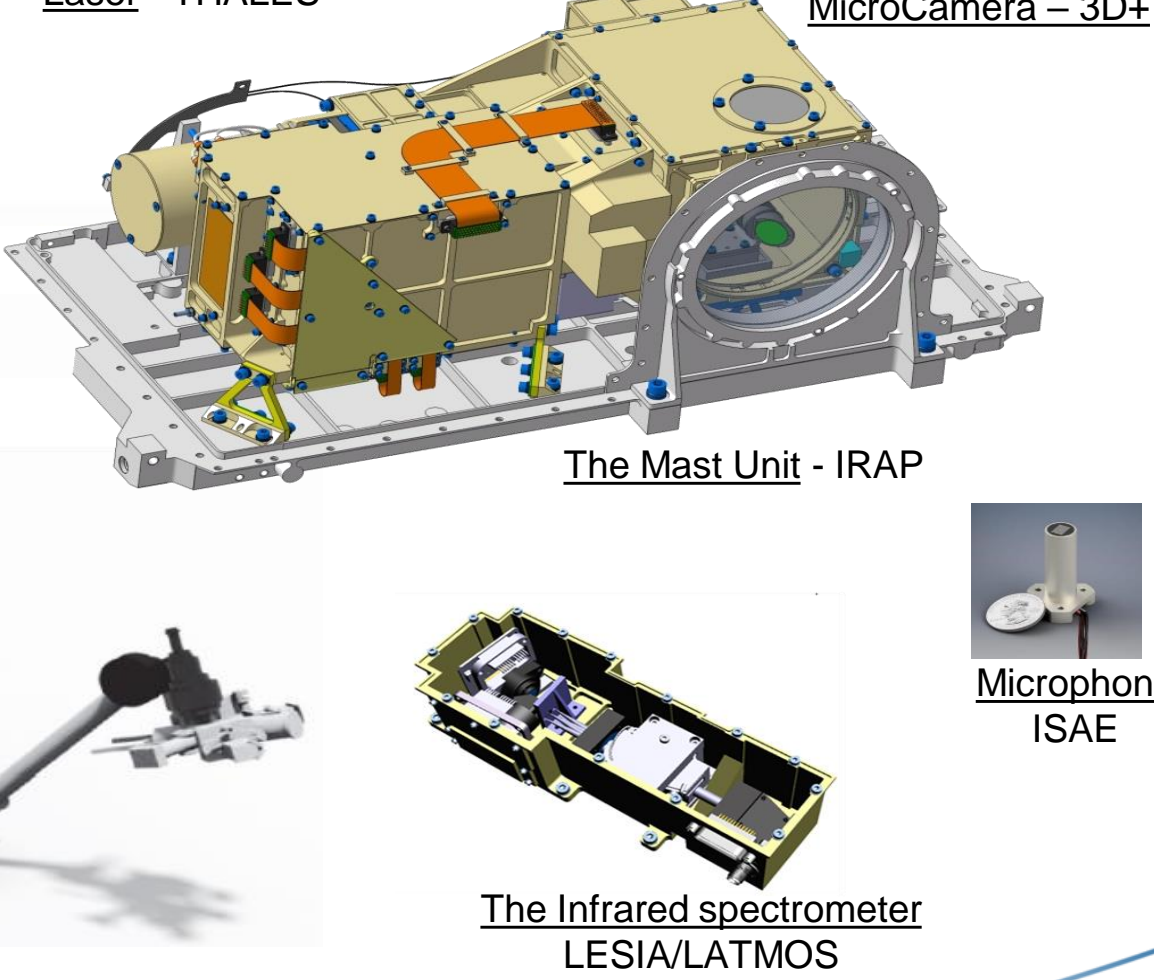

Microphone ISAE

$$
\text { LESIA/LATMOS }
$$




\section{Hayabusa 2 / Mascot}

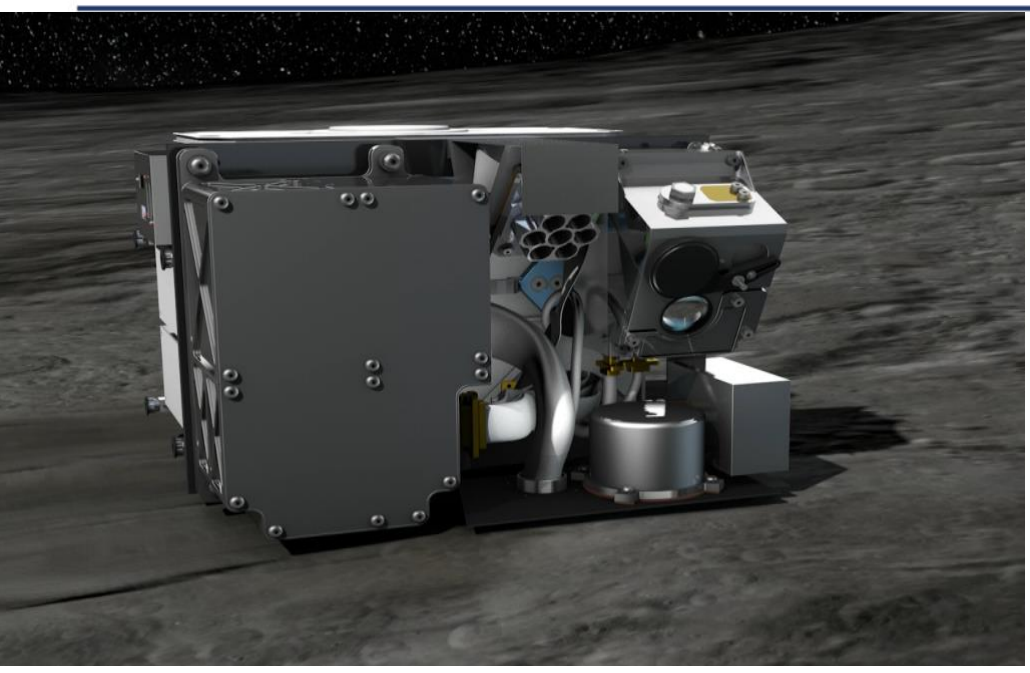

JAXA-CNES collaboration :

Micromega provided by IAS

DLR-CNES cooperation for rover delivery

Analyze composition of Ryugu asteroid

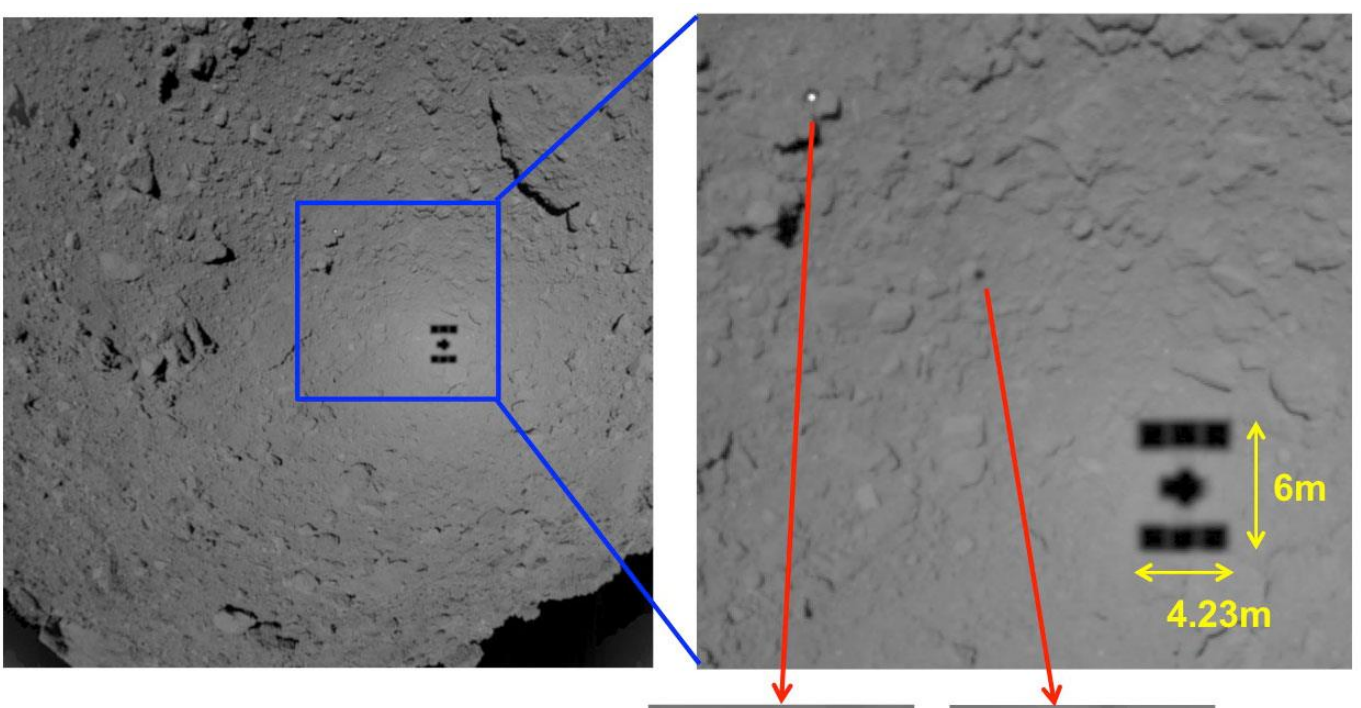
Collect samples and bring them back to earth

Mascot developped by DLR and CNES landed on Ryugu on 3 october 2018 


\section{Mission Profile}

Interplanetary flight takes about 1 year for outward/homeward.

Trade-off study on the mission profile and spacecraft system results in

5 years trip by use of chemical propulsion system.

The mission study proceeds targeting the launch in JFY2024.

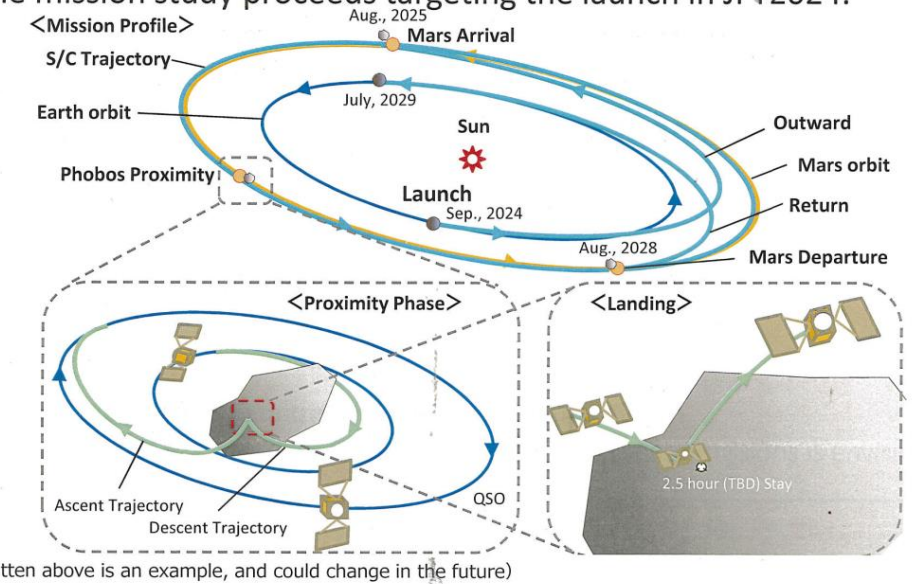

JAXA-CNES collaboration :

Macromega provided by IAS (micromega heritage) DLR-CNES cooperation for rover delivery

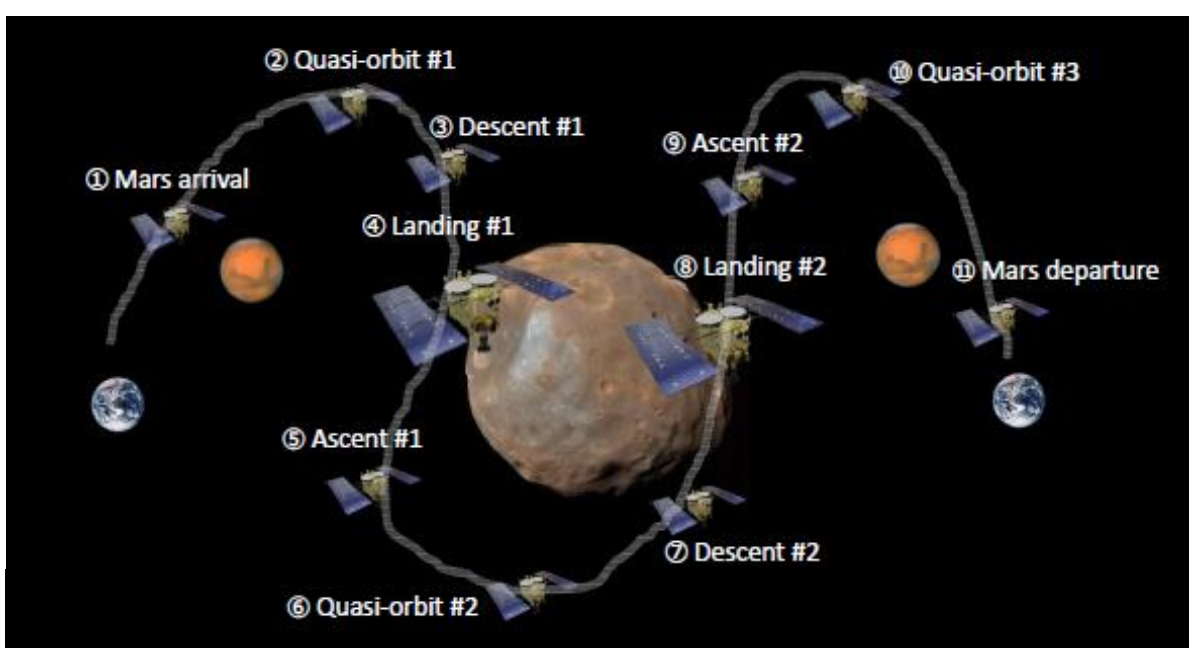

-Global Phobos mapping

-Detailed mapping of potential landing sites on Phobos -Landing and sampling collection from Phobos with rover -Deimos flyby -Back on Earth with Phobos samples
Launch: mid 2024

Arrival around Mars : mid 2025 Leave from Mars : mid 2028 Back on Earth: mid 2029 


\section{Sun, heliosphere, magnetospheres}

\section{TARANIS}

Observing energy phenomena in the upper layers of the atmosphere

Taranis will study :

$\downarrow$ sprites, jets and elves

$\downarrow$ Gamma-ray flashes from Earth

$\downarrow$ electrical and magnetic emissions

$\downarrow$ high-energy electron beams

$\checkmark$ CNES is the contracting authority for the mission, and for integration of the payload on the Myriade bus. It is also conducting tests.

$\checkmark$ The instruments are being built by the LPC2E, the CEA, IRAP, the APC and LATMOS, with Czech and Polish contributions.

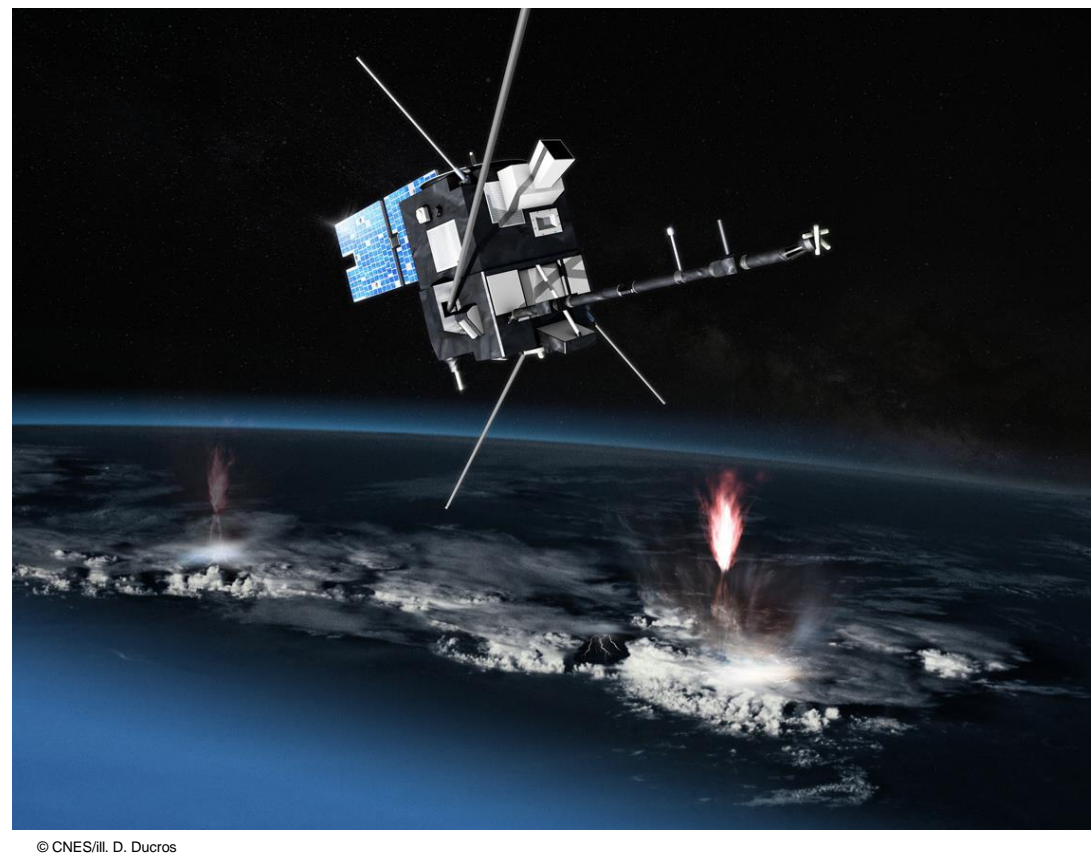

(๑) CNESSill. D. Ducros

\section{Launch scheduled end 2019}



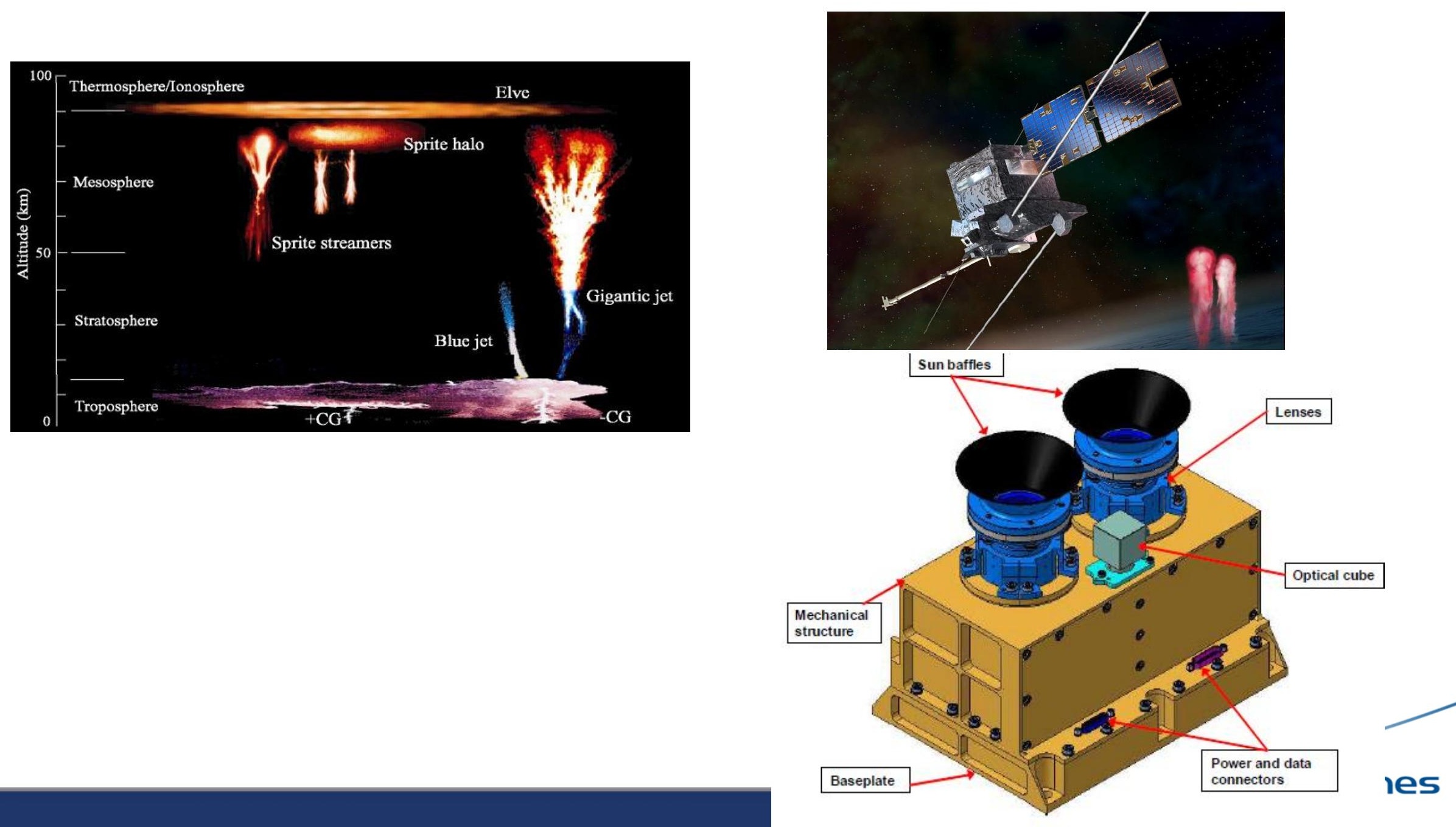
1982 Participation in definition of STAR equipment (Silex Project)

>2010- ... Propagation Studies in order to:

$\checkmark \quad$ Find optimum ground sites for FSO reception (geographical diversity)

$\checkmark$ Model atmospheric turbulence effects Characterize the degradation due to low elevation FSO transmission

$\checkmark$ Evaluate impact of molecules and aerosols

$\checkmark$ Define turbulence mitigation techniques

>2011- 2019 Study of Free Space Optical Transmission architecture at $1550 \mathrm{~nm}$

$\checkmark \quad$ Budget Link analysis

$\checkmark$ Pointing Acquisition \& Tracking (PAT) mechanism study

$\checkmark \quad$ Identification of critical components for space equipment

- 2017-2019 10W Optical amplifier prototype CILAS @ $1,5 \mathrm{~mm}$

- 2017-2019 WDM study and space evaluation
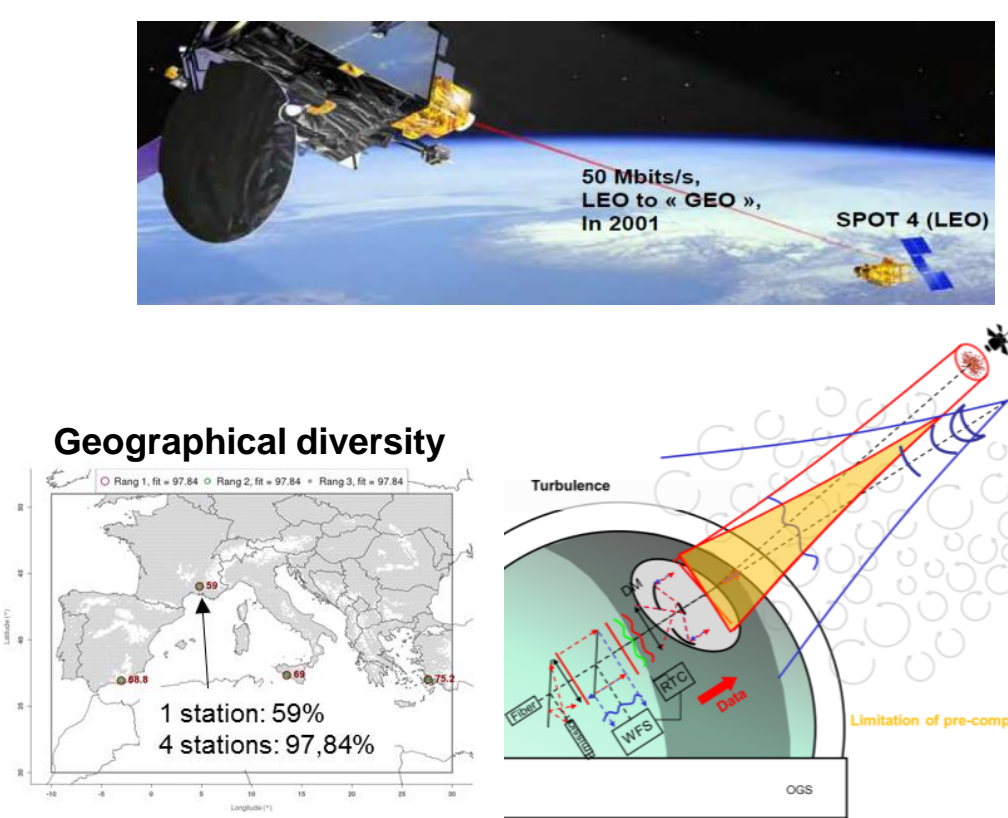

os

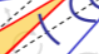

Point ahead angle

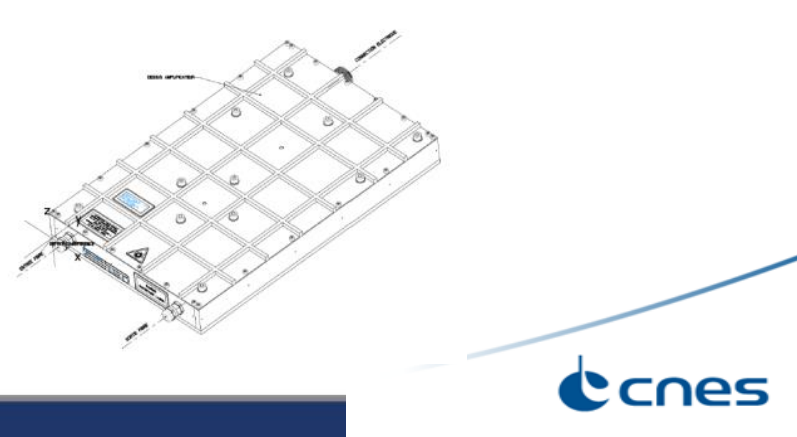


2012 - 2019 Research on transmission schemes:

$\checkmark$ Optimal modulation/coding for FSO transmission to increase transmitted data volume

$\checkmark$ Error correcting code and interleaving at high data rate

$>2015-2019 \ldots$ Demonstration of LEO to ground links

$\checkmark 2015$ Successful experimentations with earth FSO transmission/reception based on SOTA / SOCRATES (NICT) from an experimental OGS operated by OCA

$\checkmark 2016$ Successful link with NASA's OPALS on the ISS and OGS operated by OCA

$\checkmark 2018$ planned links with DLR's OSIRIS2 on Biros and OGS operated by OCA

$>2017-2019$ CUSCO phase B1 to design \& mitigate major technical risks (TRL 5) on future photonic payloads for broadband SatCom applications

$>2018$ - 2020 DYSCO phase A to identify \& design SatCom systems taking benefits from bidirectional Earth-to-Ground optical links
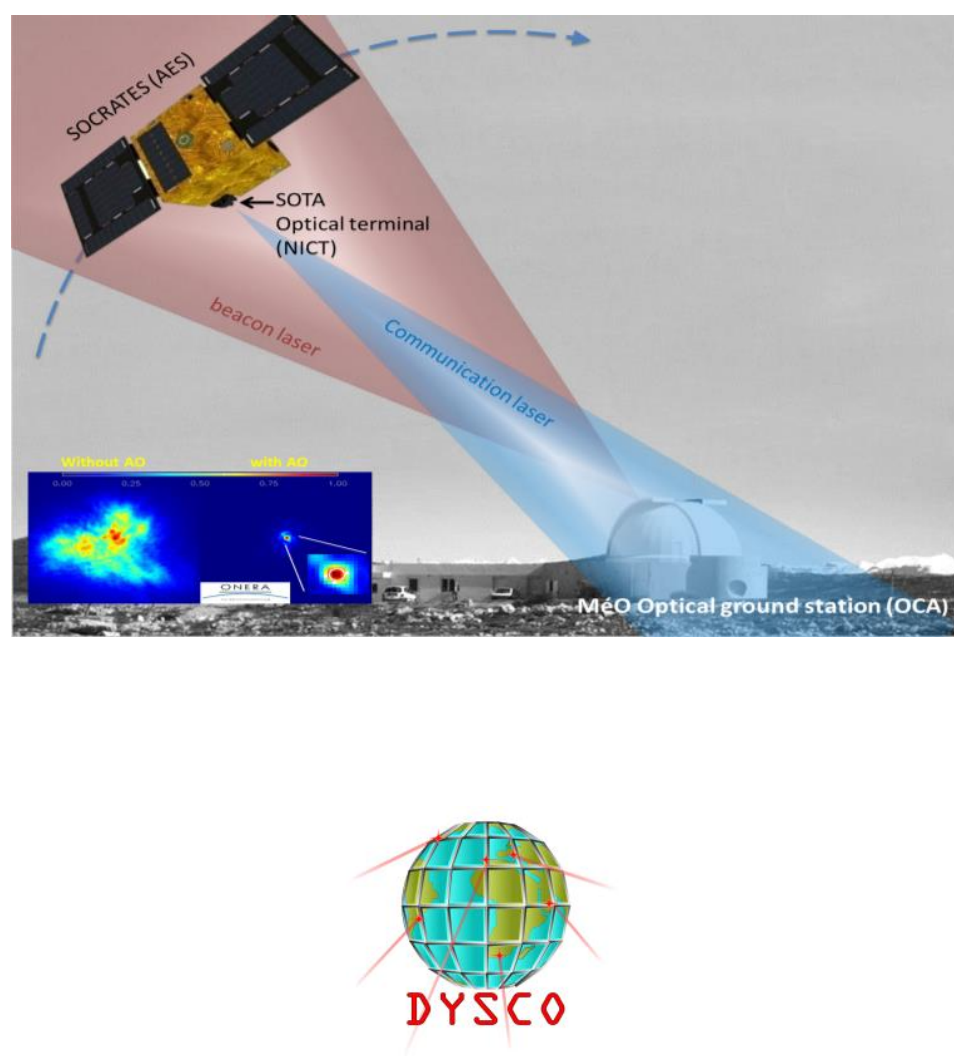


\section{THANK YOU FOR YOUR ATTENTION}

d

cnes 